NBSIR 75-771(R)

\title{
An Evaluation and Assessment of Existing Data and Procedures for the Measurement of Noise from Buses
}

\section{Applied Acoustics Section}

Institute for Basic Standards

National Bureau of Standards

Washington, D. C. 20234

September 1975

Final Report

\section{Prepared for}

Office of Noise Abatement and Control U. S. Environmental Protection Agency Washington, D. C. 20460 


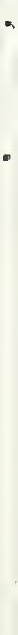




\section{AN EVALUATION AND ASSESSMENT \\ OF EXISTING DATA AND PROCEDURES \\ FOR THE MEASUREMENT OF NOISE \\ FROM BUSES}

Applied Acoustics Section

Institute for Basic Standards

National Bureau of Standards

Washington, D. C. 20234

September 1975

Final Report

Prepared for

Office of Noise Abatement and Control

U. S. Environmental Protection Agency

Washington, D. C. 20460

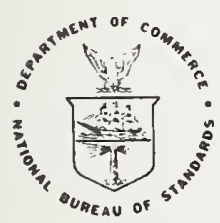

U.S. DEPARTMENT OF COMMERCE, Rogers C.B. Morton, Secretary James A. Baker, III, Under Secretary

Dr. Betsy Ancker-Johnson, Assistent Secretery for Science and Technology

NATIONAL BUREAU OF STANDARDS, Ernest Ambler, Acting Director 

Executive Summary . . . . . . . . . . . . . . . ii

I. Introduction and Scope . . . . . . . . . . . . . . I

2. Bus Description and Design ............... 2

2.1. Definition ............... 2 2

2.2. Industry Structure .............. 2

2.3. Design Characteristics ........... 4

3. Effects of Noise and Parties Affected ........... 5

4. Major Noise Sources . . . . . . . . . . . 6

5. Modes of Operation .............. . 7

6. Existing Measurement Procedures .. . . . . . . . . 7

6.1. Exterior Noise . . . . . . . . . . . . 7

6.2. Interior Noise . . . . . . . . . . I0

7. Data Base and Correlations ............... 12

8. Overview of Bus Noise Measurement Difficulties ........ I3

8.1. Classification ............... . . 13

8.2. Relation of Physical Measures to Effects/Normal Use . . . I3

8.3. Quantity Measured .............. . I4

8.4. Acoustic Environment . . . . . . . . . . . . 15

8.5. Instrumentation . . . . . . . . . . . 16

8.6. Alternative Test Procedures . . . . . . . . . . . 17

9. Appendix A. A Discussion of Bus Subsource Noise....... I8

10. Appendix B. Existing Bus Noise Measurement Procedures . . . . 24

II. Appendix C. Bus Noise Reduction: Domestic and Foreign. . . . 39

12. References . . . . . . . . . . . . . . . 39

13. Bibliography .................. . . 42 
EPA is charged with taking strong, comprehensive action to protect public health and welfare from increasing noise. Accordingly, the Agency initially identified medium and heavy trucks and portable air compressors as major noise sources and promulgated noise emission regulations covering these products. Additional products have recently been identified as major noise sources, including buses. For the purposes of this discussion buses can be defined as motor vehicles (other than taxicabs) designed for carrying more than ten passengers which are used for the transportation of persons for compensation, including intracity, intercity, school and specialty buses.

As was the case for medium and heavy trucks, bus noise can be categorized as the noise produced by the power plant [including the engine, exhaust, intake, cooling fan, etc.] and by the tire-road interaction. The noise from the power plant increases as the engine speed (and power) increases while the noise from tires increases as the vehicle speed increases. Maximum power-plant noise usually occurs when the engine is delivering maximum power at its maximum operating speed. The percentage of time a bus spends at maximum noise conditions is determined by the vehicles power-to-weight ratio and operating conditions such as acceleration, speed, load, grade and to some extent, the manner in which the bus is operated.

This report reviews existing bus noise measurement procedures with regard to their usefulness in the regulation of bus noise as well as the availability, extent and applicability of existing data. On the basis of this review, the following probable or potential measurement difficulties have been identified that could hinder the promulgation and/or enforcement of future EPA regulations to control the noise emission from buses.

- AN AIMOST NON-FXISTENT DATA BASE. Very limited data exist in the public domain on the noise levels associated with bus operations. This is due, in part, to the fact that in the United States, medium and heavy duty trucks and buses are tested according to the same test procedure which has associated with it a single recommended sound level to be met by both trucks and buses. Since medium trucks and buses tended to be quieter than heavy trucks under the operational test conditions specified -- low speed acceleration passby (high engine speed, low vehicle speed) -- the majority of the emphasis has been placed on research and development programs aimed at reducing heavy truck noise.

LACK OF TYPICAL USAGE DATA. In order to develop an appropriate, reliable and repeatable test procedure, it is necessary to consider the range of possible bus operational modes. What is needed is definition of the percentage of time which a bus typically spends at idle, accelerating, decelerating, at low speed cruise, at high speed cruise, at wide open throttle, etc. Such typical usage data do not presently exist for buses. 
MEED TO COMSIDER A CURBSIDE TEST. Since many of the people affected by bus noise are out-of-doors and in close proximity to the buses, the noise levels to which they are exposed can be much higher than those typically measured by existing U. S. standara procedures which utilize a reasurement location 50 feet $(15.2 \mathrm{~m})$ from the centerline of the bus. There exists a need to develop a curbsice test to assess impact of noise on pedestrians and for correlation of such data witi conventional [50 foot ( $15.2 \mathrm{~m})$ ] data to determine if both tests are needed.

IEED TO DEVELOP AI IN-VEHICLE TEST. There exists a need to develop an in-venicle test to assess the impact of noise on passengers. (Bus drivers are covered under the Bureau of Hotor Carrier Safety Regulations which establish a maximum interior sound level for buses operated in interstate comerce. Presumbly the remainder of the bus drivers rould be covered by the OSEA regulations.)

IESD TO ACCOUNT FOR ENIRONIEITAL/SITE EFFECTS. There is \& need for the various environmental and test site effects on noise generation, radiation and/or propagation to be systematically investigated and correction factors developed so that measurements made under any conaitions may be corrected to a single standard set of conditions. If correction factors are not feasible then there is a need for a site calibration procedure or definition of limiting test conditions.

MEED FOR SIIPLER TEST PROCEDURE. There exists a need to develop a test procedure that is simpler to perform and is less dependent on weather and test site variables. Correlation should be established between the results obtained utilizing such a test and human response to bus noise.

-IEED TO SPECIFY TRAISIENT RESPOISE OF INSTRUIEITATION YORE ACCURATELY. There exists a need to measure the response of existing instrumentetion to actual transient signals, e.g., a bus passby, in order to establish the interrelationships among the rarious precision instruments, to supply data to strengthen existing standards, ana to establish a data base so that the technical comunity, manufacturers, lammers anc enforcement agencies will have a common basis for comparison of results obtained using supposedy comparable equipment.

In summary, it is doubtful that the data in the open literature are extensive enough to provide EPA with the information needed for a comprehensive analysis of the economic costs and technical feasibility associated with a given regulation. Furthermore, there are practically no data available upon which to base an evaluation of alternative bus noise measurement procedures or to establish correlations between the noise associated with various operational modes and the noise measured utilizing various test procedures.

Thus, it appears that EPA should generate an extensive physical data Dase and investigate altemative measurement procedures prior to formulation of the liotice of Proposed Rule laking. 
An Evaluation and Assessment of Existing Data and Procedures for the Measurement of Noise From Buses

This report reviews existing bus noise measurement procedures with regard to their usefulness in the regulation of bus noise as well as the availability, extent and applicability of existing data. On the basis of this review, probable or potential measurement difficulties are identified that could hinder the promulgation and/or enforcement of future EPA regulations to control the noise emission from buses.

Key Words: Acoustics (sound); bus; measurement methodology; noise emission standard, noise measurement.

\section{Introduction and Scope}

The National Bureau of Standards (NBS), under the sponsorship of the Office of Noise Abatement and Control (ONAC), U. S. Environmental Protection Agency, has attempted to identify probable or potential measurement difficulties that could hinder the promulgation and/or enforcement of future noise regulations to control the noise emissions from buses. A search of the open literature in conjunction with numerous personal contacts established the basis for discussion of:

1. The basic characteristics of bus design and construction.

2. The effect of bus noise and the parties affected.

3. The major component noise sources for buses.

4. The normal or typical mode of operation characteristic of the various classes of buses.

5. The usefulness of existing measurement procedures for regulation of the noise from buses considering the viewpoint of EPA, manufacturers and enforcement personnel.

6. The availability, extent and applicability of existing data that could be utilized by EPA in their efforts to promulgate noise emission regulations for buses.

This report is limited to those factors affecting the measurement of bus noise. EPA/ONAC will independently investigate the technical

feasibility and economic implications of bus noise regulation. Also, it is assumed that the strategy followed during the development of the new truck regulation -- namely, that tires will be identified separately as a major noise source -- will apply to all vehicular noise sources; therefore, this report concentrates on measurement procedures for measuring the noise of buses, excluding tires. 


\subsection{Definition}

The Federal Highway Administration, U. S. Department of Transportation, Motor Carrier Safety Regulations[1] " defines a bus as "any motor vehicle designed, constructed, and used for the transportation of passengers; including taxicabs." A slightly modified definition, which excludes taxicabs, was proposed by the Task Force on Noise to the State of Illinois, Institute for Environmental Quality[2]. They defined a bus as a "motor vehicle designed for carrying more than 10 passengers; and every motor vehicle, other than a taxicab, designed and used for the transportation of persons for compensation." The latter definition will be utilized throughout the remainder of this report.

It is also important to review the definition of "completed vehicle" according to the National Highway Traffic Safety Administration, U. S. Department of Transportation[3]. A completed vehicle is defined as "a vehicle that requires no further manufacturing operations to perform its intended function, other than the addition of readily attachable components, such as mirrors or tire and rim assemblies, or minor finishing operations such as painting." Since most "bus" marufacturers do not fabricate bus bodies, the majority of "buses" coming off the assembly line do not meet the criterion to be called complete vehicles. Such vehicles are termed "incomplete vehicles" and are defined as "an assemblage consisting as a minimum, of frame and chassis structure, power train, steering system, suspension system, and braking system, to the extent that those systems are to be part of the completed vehicle, that requires further manufacturing operations, other than the addition of readily attachable components, such as mirrors or tire and rim assemblies, or minor finishing operations such as painting to become a completed vehicle"[3]. For the purposes of this report, complete and incomplete buses will be considered and will be referred to simply as buses.

\subsection{Industry Structure}

An extensive survey of current data on the bus population in the United States and bus sales information for the current year was not made. Data compiled in 1974[4,5] indicates that the bus population is comprised of approximately 79 percent school buses, 12 percent intracity buses, 5 percent intercity buses and 4 percent special purpose buses (see Table 1).

Manufacturers of buses can be categorized into two distinct groups -large companies that also produce trucks and/or automobiles and small custom assemblers. The large companies utilize their research and manufacturing expertise to adapt their engines and chassis to the needs of the bus market. The large manufacturers are particularly attracted to the school bus market because of the large volume of sales and the fact that this segment of the market readily lends itself to the "assembly line concept" of manufacturing due, in part, to less restrictive passenger

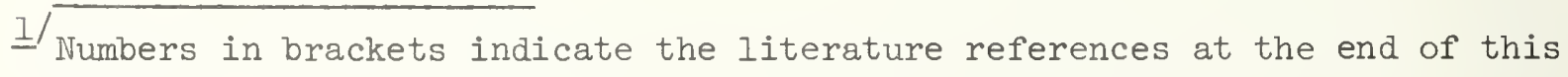
report. 
Table I. Total number of buses in the United States as of $1973[4]$.

\begin{tabular}{|l|c|c|}
\hline \multicolumn{1}{|c|}{ Tyoe } & liumber & Percentege \\
\hline School & 333,892 & 79 \\
Intrecity & 50,000 & 12 \\
Intercity & 20,600 & 5 \\
Special Purpose & 18,872 & 4 \\
Iotel & 423,364 & 100 \\
\hline
\end{tabular}

Jable 2. Uanufacturers of intracity, intercity end school busesi5].

\begin{tabular}{|c|c|c|}
\hline $\begin{array}{l}\text { lanufacturens of } \\
\text { Intracity Euses }\end{array}$ & Total Sales 1972 & $\begin{array}{l}\text { Yarizet Share (1972) } \\
\text { Percentage }\end{array}$ \\
\hline $\begin{array}{l}\text { GeneraI Yotors } \\
\text { Flexibie Compar. } \\
\text { H' General }\end{array}$ & $\begin{array}{l}1500 \\
1200 \\
\frac{--}{2700}\end{array}$ & $\begin{array}{l}56 \\
44 \\
-- \\
100\end{array}$ \\
\hline \multicolumn{3}{|l|}{$\begin{array}{l}\text { Yanufacturers of } \\
\text { Intercity Buses }\end{array}$} \\
\hline $\begin{array}{l}\text { Ootor Coech Inäustries* } \\
\text { 3us anc Car Conpany* } \\
\text { General Votors } \\
\text { Others }\end{array}$ & $\begin{array}{l}100 \\
300 \\
250 \\
150 \\
1100\end{array}$ & $\begin{array}{l}36 \\
27 \\
23 \\
14 \\
100\end{array}$ \\
\hline \multicolumn{3}{|l|}{$\begin{array}{l}\text { Yarufacturers o: } \\
\text { School Suses }\end{array}$} \\
\hline 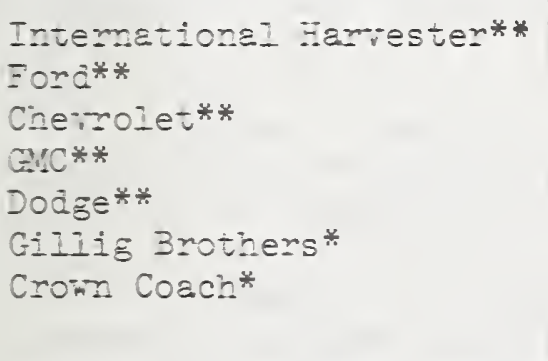 & $\begin{array}{r}13,550 \\
8,150 \\
3,750 \\
3,150 \\
1,400 \\
200 \\
150 \\
30,350\end{array}$ & $\begin{array}{l}45 \\
27 \\
12 \\
10 \\
5 \\
0.5 \\
\frac{0.5}{100}\end{array}$ \\
\hline $\begin{array}{l}\text { * (Cavegory I - Iarge Pro } \\
\text { * (Category II - Small Pr }\end{array}$ & $\begin{array}{l}\text { rst } \\
\text { ers) }\end{array}$ & \\
\hline
\end{tabular}


preference. On the other hand, the small companies design particular configurations to meet the specialized demand of specific customers.

Ninety-nine percent of the school buses in the United States are manufactured by International Harvester Company, Ford Motor Company, General Motors Corporation -- Truck and Coach and Chevrolet Divisions, and Chrysler Corporation -- Dodge Division. These companies do not manufacture bus bodies but supply only the chassis and gasoline powerplant for school buses. Two small manufacturers -- Gillig Brothers and Crown Coach -fabricate both the chassis and the bus body and also provide the option of either a gasoline or diesel powerplant.

During 1972, 100 percent of the intracity (urban transit) buses manufactured in the United States were produced by either General Motors Corporation or the Flexible Company. Since then, AM General, a subsidiary of American Motors, has entered the market.

Motor Coach Industries, Bus and Car Company and General Motors manufactured 86 percent of the intercity highway buses (see Table 2) produced in the United States in 1972. The remaining 14 percent were manufactured by AM General, Flexible Company and Crown Coach. There is also a group of manufacturers who produce only school bus bodies. These include Blue Bird Body Company, Carpenter Body Works, Inc., Superior Coach Division of Sheller-Globe Corporation, Perley A. Thomas Car Works, Inc., Ward School Bus Manufacturing, Inc., and Wayne Corporation, to name fust a few $[5,6]$.

\subsection{Design Characteristics}

One convenient categorization for buses is with respect to their intended use -- (1) intracity transit buses, (2) intercity highway buses, (3) school buses and (4) specialty buses utilized for airport service, touring, etc. Each type of bus has its own market and specialized engineering characteristics. For example, nearly all school buses are gasoline powered, while most intracity, intercity and special purpose buses are diesel powered. For the purpose of this report, trolleys and streetcars are excluded.

Intracity buses (which operate in urban and suburban areas) are typically 2-axle buses powered by either a Detroit Diesel. 6V-71 engine or a Detroit Diesel 8V-71 engine. These are 2-cycle diesel engines with mechanically driven blowers to provide forced air induction. The radiator, engine and transmission comprise a powerplant unit which is usually mounted transversely across the extreme rear of the bus. The radiator is mounted on the left-side (street side) in the rear while the automatic transmission is located on the right side (curb side) of the engine compartment. Usually an axial flow fan is mounted on the front of the engine, just inboard of the radiator. The exhaust exit (specified by the customer) is either at street level or high level.

Intercity buses (which primarily operate on highways) are 2- and 3-axle coaches that usually utilize a Detroit Diesel 8V-71 engine mounted 
longitudinally in the rear of the bus with the front of the engine facing the rear of the coach. They differ from intracity buses in the fact that they contain cargo or luggage compartments in the under carriage of the bus. A single radiator on the left side (street side) in the rear with an axial flow fan or two radiators (one on each side of the bus) and two "squirrel cage" blowers are generally used to provide cooling. Single and dual muffler systems and both automatic and manual transmissions are available.

School buses are nearly identical, except for the body, to medium ducy trucks. They utilize redium duty truck chassis and gasoline engines mounted in the front of the bus -- although rear and midale engine configurations are produced by some manufacturers. As is the case for trucks, school buses utilize \& forward mounted radiator and a single speed axial How engine cooling fan. The engine is muffled at the intake by an air cleaner and at the exhaust port by a single, horizontal muffler and a long tail pipe.

Because most studies in the past grouped special purpose buses with intercity buses, little data exist on the wide range of special purpose buses which are utilized for sightseeing, tours, airport transportation, etc. The increased use of "minibuses" requires that special purpose buses be broken out as a separate category in future investigations.

\section{Effects of Noise and Parties Affected}

In general, the noise from buses tends to annoy fewer people than any other vehicular noise source; however, the intensity of their noise emissions tends to be greater[7]. The persons who potentially are adversely affected by the noise from buses include the operator and passengers on the bus, passengers waiting at bus stops, other pedestrians, other motorists, and persons living or working along the bus route. The noise from buses can interfere with speech comunication; lead to distraction or other kinds of task interference; disrupt sleep, rest and recreation; and, in the case of bus drivers and long distance commuters, potentially contribute to the risk of hearing damage and to other possible Dhysiological effects. Another factor which must be considered is that since most of the people affected may not receive any benefit from the bus service, their tolerance for bus noise is likely to be lower than that of a regular bus user.

Since many of the people affected by bus noise are out-of-doors and in close proximity to the buses, the noise levels to which they are exposed can be much higher than those typically measured by existing U. S. standard procedures which utilize a measurement location 50 feet ( $15.2 \mathrm{~m}$ ) from the centerline of the bus. In addition, the "canyon effect" which results in a build-up of reverberent sound in city streets bounded by fairly tall buildings, can lead to even rather distant listeners being exposed to hioher noise levels than might be expected. These factors need to be carefully considered when developing appropriate measurement methodologies as well as when assessing the impact of bus noise on the population. 
It is important to identify the major sources of noise in buses and the effect of normal operation on the noise levels associated with each of these sources. Buses have essentially the same major noise sources as trucks. The primary difference lies in the location of the major noise components and the shielding provided by the body. Basically the sources are as follows:

Engine (Mechanical) Noise - is primarily produced by the combustion process which produces rapid changes in pressure in the cylinder which in turn results in excited mechanical vibration in the engine structure. Some of this vibrational energy is subsequently radiated to the atmosphere as acoustic energy.

Fan Noise - is the result of air flow past the fan blades which results in rotational (associated with pressure differences across the fan blades) and turbulent noise (associated with the eddy flows and vortices shed at the blade edges). Such noise is related to fan tip speed and air distribution which is governed by the fan configuration and environment. It should be noted that buses equipped with rear engines usually have their fans located on the left hand side (street side) of the vehicle.

Exhaust Noise - is created when high pressure exhaust gases, released through the engine exhaust valves, excite oscillations in the exhaust system which are radiated to the atmosphere at the tail pipe, through the pipe surfaces and through the muffler shell. The noise is a function of engine type, engine timing, valve duration time, intake system type, muffler type, size and location, pipe diameter, pipe bends, dual or single system, etc.

Air-Intake Noise - is created by the opening and closing of the intake valve which causes the volume of air in the system to pulsate. Associated noise levels are dependent upon whether the engine is gasoline or diesel, turbocharged or naturally aspirated, 2-cycle or 4-cycle, the number of cylinders, the engine displacement, engine rpm, engine load, etc.

- Tire-Road Interaction Noise - is related to tire and tread configuration, road surface texture, vehicle speed, load and state of tire wear. Vibration of the tire carcass and the entrapment and release of air from tread/pavement interstices appear to be the major mechanisms for tire noise generation.

- Transmission Noise - arises from the meshing of gear teeth in transmission systems and may be apparent under load, no load, or reverse load conditions. The noise may be aggravated by resonance of the gearbox casing or by structure-borne components that excite large body surfaces that act as efficient radiators. 
Noise from Accessories - is created by blowers, brakes (squeal, air brake release), generators, air conditioning equipment or miscellaneous equipment such as access and cargo area doors.

Appendix A contains a more detailed discussion of the component noise sources.

\section{Modes of Operation}

The noise impact of intracity, intercity, school and special purpose buses depends on the range of possible operational modes and the amount of time they spend in the community. Intracity buses, for example, operate almost exclusively in business or residential areas. They normally operate on streets with posted maximum speed limits of $30 \mathrm{mph}(48.3 \mathrm{~km} / \mathrm{hr})$ or less, and stop at passenger pick-up points as well as for traffic -- thus, they accelerate and decelerate frequently. On the other hand, many intercity buses spend a major portion of their time operating on the open road and only infrequently enter business and residential areas, e.g., to pick-up or leave off passengers or cargo at urban depots. These buses normally operate at cruise speeds in excess of $35 \mathrm{mph}(56.4 \mathrm{~km} / \mathrm{hr})$ on the highway where tire noise becomes a more significant, if not the dominant, noise source. Operations of school buses are limited to whatever the posted speed limits happen to be in the urban, suburban or rural area in which they operate. Like intracity buses, they make frequent stops at passenger pick-up points as well as for traffic. School buses accelerate and decelerate frequently; however, on occasion, they maintain cruise speeds in excess of $35 \mathrm{mph}(56.4 \mathrm{~km} / \mathrm{hr})$ on highways .

In order to develop appropriate, representative, reliable and repeatable test procedures for determining the noise output of buses, it is appropriate to consider the various operational modes of each type of bus and the noise level associated with each particular operational mode. This suggests that each type of bus be assessed under normal operating conditions in terms of the actual percentage of time typically spent at idle, acceleration, deceleration, low speed cruise, high speed cruise and wide open throttle. Such a comprehensive analysis of the various operational modes of buses does not presently exist.

\section{Existing Measurement Procedures}

In this section, the existing measurement procedures which are relevant to determination of the noise emission from buses are presented and compared.

\subsection{Exterior Noise}

There are basically three existing measurement standards that are applicable to the measurement of the exterior noise produced by buses . are: 
(1) Society of Automotive Engineers (SAE) Standard J366b -- Exterior Sound Level for Heavy Trucks and Buses[8],

(2) International Organization for Standardization (ISO) Recommendation R362 -- Measurement of Noise Fmitted by Vehicles[9], and

\section{(3) California Highway Patrol (CHP) Noise Measurement Procedure[10].}

To facilitate a discussion of these measurement procedures a table -Table 3 -- has been developed which outlines the pertinent sections of each of the test methods. This table serves as the basis for comparison among the three procedures. Complete texts of these standards are reproduced in Appendix B.

The SAE J366b procedure is the principal standard used in the United States for measuring the exterior noise from buses. This standard was designed to extract the maximum noise that can be produced by the propulsion system without considering the influence of tire noise. The noise level produced during such a test represents the worst-case noise level for a bus operating under urban driving conditions. Such a test also represents the worst-case propulsion-system noise contribution to the over-all noise levels produced by buses at high speeds. This standard is intended as a design tool and as such the standard recommends that a maximum A-weighted sound level of $88 \mathrm{~dB}$, when measured in accordance with J366b procedures, be used as a reference in the design and development of heavy trucks and buses. In addition a $2 \mathrm{~dB}$ allowance is recommended for variations in test site, temperature gradients, test equipment, and inherent differences in nominally identical vehicles.

The CHP procedure (implementing Section 27160 of the Vehicle Code which applies to the measurement of noise from new motor vehicles, including buses, offered for sale in the State of California) is very similar to the SAE procedure. However, since the vehicles covered by the CHP test include motorcycles, passenger cars and light trucks, in addition to medium and heavy trucks and buses, the specification of the test site geometry in the CHP procedure differs from that specified in the SAE standard. The CHP test site is basically a compromise combination of the test sites specified in SAE J366b (heavy trucks and buses), SAE J 986a (passenger cars and light trucks) and SAE XJ33la (motorcycles). Another difference occurs in the instrumentation requirements. CHP allows the use of Type 2 or S2A instrumentation in lieu of Type 1 (precision) equipment for enforcement purposes.

ISO R362 is the applicable international standard for the measurement of exterior bus noise. The use of this standard is especially widespread in Europe. This standard also allows the use of essentially Type 2 instrumentation. Although all motor vehicles are covered by the standard (as was the case with the CHP procedure), the test site geometry is very 


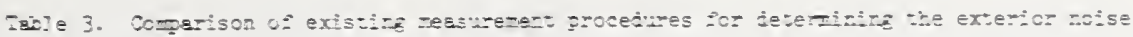
o: bus

\begin{tabular}{|c|c|c|c|}
\hline SELEDEO & $S: \pm \sqrt{3660}$ & $C E=$ & zSO $\approx \equiv E z$ \\
\hline $\begin{array}{l}\text { Teificies corerez by } \\
\text { sta-card }\end{array}$ & $\begin{array}{l}\text { Irics, tzict trectors } \\
\text { sud buses }\end{array}$ & A1I motor rehicies & $\therefore$ n atcr reizoies \\
\hline Instrzen:evion & 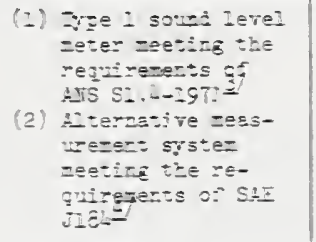 & 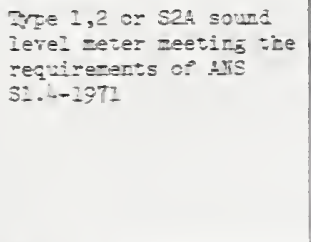 & 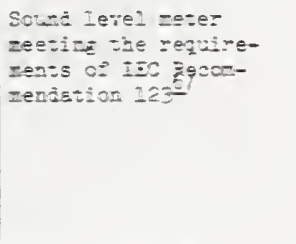 \\
\hline Test Site & 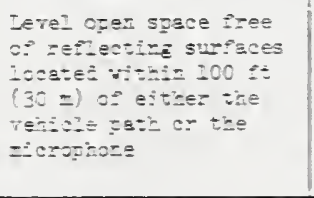 & 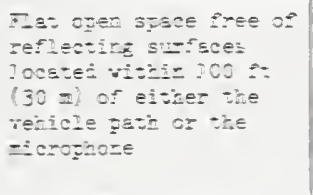 & 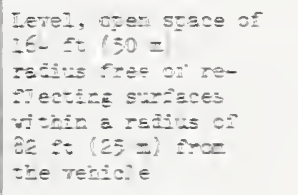 \\
\hline $\begin{array}{l}\text { Measurement } \\
\text { Irea Surisce }\end{array}$ & 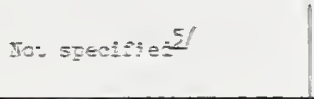 & Concreze or Esz=alt & 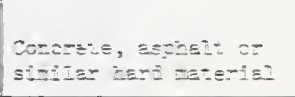 \\
\hline 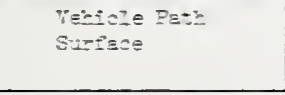 & Concrete or espial: & Concrete or ssphelt & 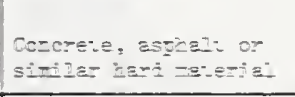 \\
\hline 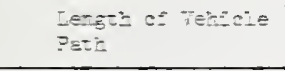 & $=00 \therefore(30=)$ & $200=60=j$ & $56 \div 20=?$ \\
\hline Exz Zoze & Lest $40=2(12=)$ & Jes= $75 \therefore 122.5=$ & To ree- eri lone \\
\hline $\begin{array}{l}\text { Acce-ers:ion } \\
\text { Boiz: }\end{array}$ & 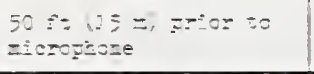 & 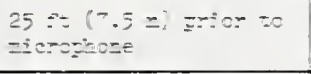 & 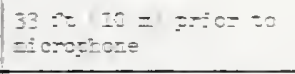 \\
\hline 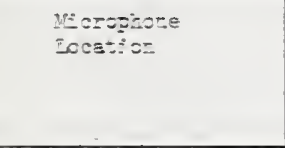 & 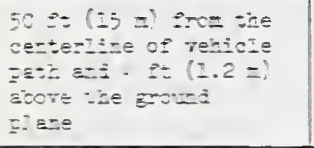 & 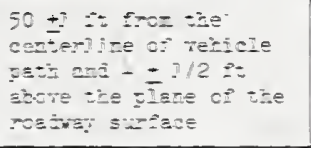 & 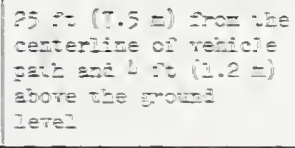 \\
\hline Vericle operezioz & 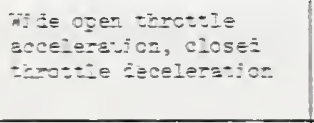 & 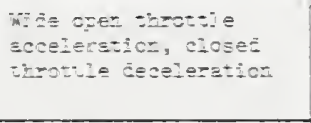 & 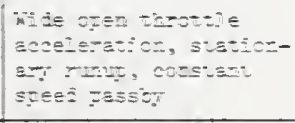 \\
\hline $\begin{array}{l}\text { Pericle } \\
\text { Befererce } \\
\text { Poiz: }\end{array}$ & 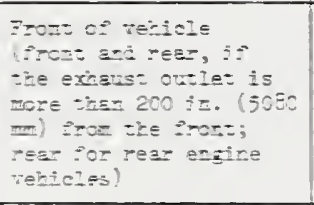 & 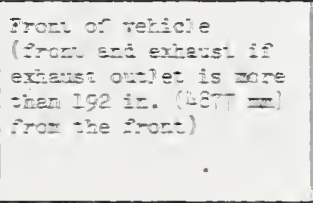 & 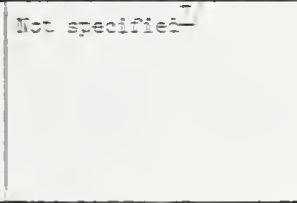 \\
\hline Quentzty Weasured & $\begin{array}{l}\text { Wexima A-veizines } \\
\text { soud I etel, Pest } \\
\text { response }\end{array}$ & 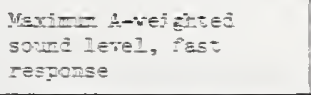 & 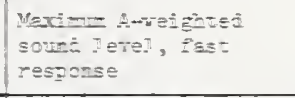 \\
\hline Reported Verue & 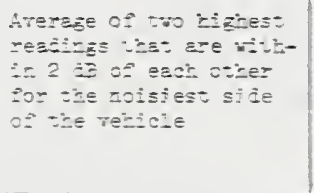 & 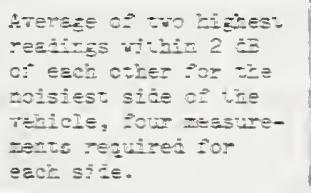 & $\begin{array}{l}\text { Two measure-e-te } \\
\text { required esch sjde, } \\
\text { all telues reported }\end{array}$ \\
\hline
\end{tabular}

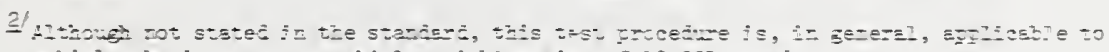

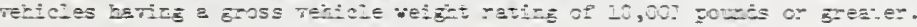

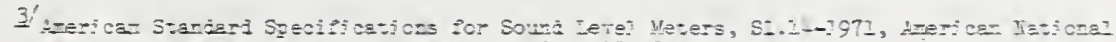
surjezs Irstinute, Tes Yori, Tew Toric (19T1)[II].

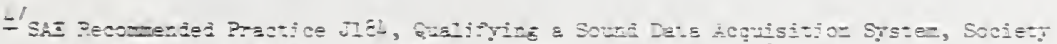

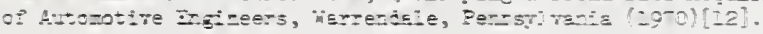

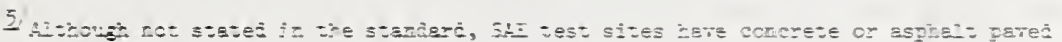
measuremez szeas.

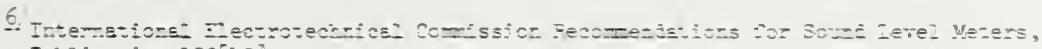
priblication $233[13]$.

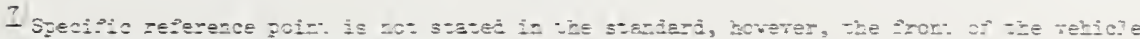
is i=ziez. 
similar to the SAE J366b site specifications. The major difference, which is a common one between international and domestic standards, is the fact that the measurements are made at $7.5 \mathrm{~m}$ (25 ft) instead of $50 \mathrm{ft}$ ( $15.2 \mathrm{~m})$, respectively.

All three of these procedures measure the same acoustic quantity; namely, the maximum A-weighted sound level with fast meter response. Also each of the three procedures utilize the wide-open throttle acceleration mode of operation as the primary test although procedures for closed throttle deceleration (SAE/CHP), stationary acceleration (ISO) and constant speed passby (ISO) tests are also outlined.

Currently within ISO, a revision of R362 is being considered. Review of a recent draft points out onlv two significant differences between the original and revised standard -- (1) the revised standard requires the use of precision instrumentation meeting the requirements of IEC Publication 179[14] and (2) the provisions for a stationary acceleration test and a constant speed passby test have been deleted. In addition to the revision to ISO $\mathrm{R} 362$, a second document is being developed which outlines a survey method for measurement of noise emitted by stationary motor vehicles. This document provides specifications for instrumentation, test sites, microphone locations and vehicle operating conditions as part of a procedure for making near-field measurements of exhaust and engine noise.

Since buses are similar to trucks in many respects, another test method which deserves attention is the stationary acceleration (or "run-up") test which is one of the tests prescribed in the Federal interstate motor carrier noise emission standards. Basically this test specifies that the vehicle should be accelerated with wide open throttle to its governed engine speed as rapidly as possible. The vehicle is stationary with its transmission in neutral. One problem with this test procedure is that its application is limited to vehicles with governed engines. Also, it should be noted that the data base showing the correlation between the stationary acceleration test and the low speed acceleration passby test specified in SAE J366b was established utilizing trucks, not buses.

\subsection{Interior Noise}

Until recently, little emphasis has been placed on measurement standards relating to motor vehicle interior noise. For instance, the first interior noise level regulation covering buses was enacted in November 1973. The provisions in the Code of Federal Regulations, Title 49 - Transportation (U. S. Department of Transportation, Federal Highway Administration), Motor Carrier Safety Regulations, Part 393.94 - Vehicle Interior Noise Levels (see Appendix B for complete text) applies to all commercial trucks and buses operated in interstate commerce. In essence, the regulation requires that the $\mathrm{A}$-weighted interior sound levels at the driver's seating position $[6$ inches $(15.2 \mathrm{~cm}$ ) to the right of the drivers right ear] not exceed $90 \mathrm{~dB}$ while the vehicle is operated at its maximum rated or governed engine speed ("high idle"). 
Table 4. Comparison of existing and groposed measurement grocedures for determining the interior noise of buses.

\begin{tabular}{|c|c|c|}
\hline STALDAEO & BMCS RECUIATIOI & $\pm \leq 0$ \\
\hline $\begin{array}{l}\text { Vehicles covered } \\
\text { by standard }\end{array}$ & $\begin{array}{l}\text { All trucks and buses } \\
\text { cperated in interstate } \\
\text { comerce. }\end{array}$ & $\begin{array}{l}\text { All rozor venicles intenced } \\
\text { for rod use including those } \\
\text { where the driver and,or } \\
\text { passengers occupy an open } \\
\text { cabin or evez only a :ell- } \\
\text { defined space. }\end{array}$ \\
\hline Instruentation & $\begin{array}{l}\text { Type } 2 \text { sound level neter } \\
\text { meeting the requiretents } \\
\text { of AvS SI.4-1971 }\end{array}$ & $\begin{array}{l}\text { Sourd letel zeter =etits } \\
\text { the recuizezetts, of IEC } \\
\text { Publicquion ITg }\end{array}$ \\
\hline Test Site & $\begin{array}{l}\text { Level oper space free of } \\
\text { reflecting objects within } \\
50 \text { feet ( } 15.2 \text { II) of the } 8 / \\
\text { driver's seeting position }\end{array}$ & $\begin{array}{l}\text { Level oger space frec of } \\
\text { reflecting objects within } \\
65 \text { leet ( } 20 \text { I) of the } \\
\text { vehicle. The test roaj } \\
\text { shall be herd and as smoth } \\
\text { and level es possiole }\end{array}$ \\
\hline $\begin{array}{l}\text { Microphone } \\
\text { Iocetion }\end{array}$ & $\begin{array}{l}6 \text { inches ( } 15.2 \mathrm{~cm} \text { ) to the } \\
\text { right of, in the seme } \\
\text { plene as, and airectly in } \\
\text { Iine wit, tile driver's } \\
\text { right ear }\end{array}$ & 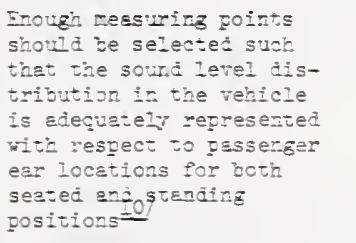 \\
\hline $\begin{array}{l}\text { Veinicle } \\
\text { ogeration }\end{array}$ & $\begin{array}{l}\text { Stationary, bigh idle } \\
\text { Tehicle stationar, } \\
\text { engine accelersted to } \\
\text { its maxitu gorerned } \\
\text { soed cr maximt reted } \\
\text { horseporer and the } \\
\text { engine is szabilized at } \\
\text { inat speed (transmis- } \\
\text { sior in netiral) }\end{array}$ & 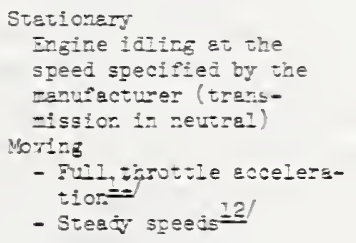 \\
\hline $\begin{array}{l}\text { Quantity } \\
\text { Weasured }\end{array}$ & $\begin{array}{l}\text { Maximu A-reighted sound } \\
\text { Ievel, Pest response }\end{array}$ & $\begin{array}{l}\text { Maximu d-weigited sound } \\
\text { level, fast respozse }\end{array}$ \\
\hline $\begin{array}{l}\text { Pezorted } \\
\text { Velue }\end{array}$ & $\begin{array}{l}\text { Average of two highest } \\
\text { reaings that are within } \\
2 \text { d8 of each other }\end{array}$ & A1: ve?tss rezorted \\
\hline
\end{tabular}

Q/ Although not specified, the intent is for the reasurement to be made rith the rehicle positioned on a hard suriece.

2/If additional reasurirg equipmert, e.z., tape recorier, graghic leve recorder, are used, they shall conform to the relevant clauses of IEC Publication $179[14]$. When measuremerts of noise spectra ere desirej, ihs pilters shall neei the reguiremens of IEC Publication 225[15].

10 l One measuring point at the driver's position. Mortelly it is sufficient to have adilional measurement points at the midile and rear of the rehivle, preferably at positions adjacent to the longituanal axis of the rehicle. The microphone is located horizctelly ei a position $0.65 \pm 0.05=$ abcre the seat and $0.2 \pm 0.02$ a to the zint (to the left for righting driven vehicles) of the middle plane of tice seet.

11/Full inrottle acceleration test -- sicbilize exgine and rehicle speed ther fully open inrottle as fast es possible recording the sound until go: of the ergine speed for taximu power or $120 \mathrm{~km} / \mathrm{h}$ is resched. (Initial opereting conditions are specified for venicles with both Eanual and auto. matic transmissions.)

$\underline{12 / 5}$

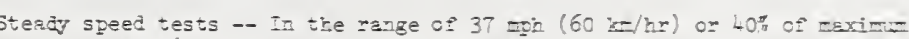
vehicle sjeec (whichever is lover) to $75 \mathrm{mph}$ (120 kJ/hr) or $80 \%$ of maximum rehicle speed (whichever is lower). A-weighted sound letels are to be deterized at at leest 5 scecus at equal intervals cotering the above rerge. 
A draft proposal for methods of measurement of noise inside motor vehicles has been developed and is presently being circulated to the member nations for voting as an ISO Draft International Standard. Rather than discuss the details of this proposed standard, Table 4 has been developed which allows comparison between pertinent sections of the Bureau of Motor Carrier Safety (BMCS) regulations and the ISO Draft International Standard.

A review of Table 4 shows the complexity -- in terms of the number of measurement positions as well as the number of vehicle operational modes to be tested -- of the proposed ISO procedure when contrasted against the single microphone location, single vehicle operational mode specified by BMCS in their regulations. However, it should be remembered that the Iso procedure applies to all motor vehicles. Therefore, one would hope that the number of tests could be reduced when only a single vehicle type, e.g., a bus, is considered.

\section{Data Base and Correlations}

Very limited data $13 /$ exist in the public domain on the noise levels associated with bus operations. This is due, in part, to the fact that in the United States, medium and heavy duty trucks as well as buses, having a gross vehicle weight rating (GVWR) of 10,001 pounds ( $4545 \mathrm{~kg}$ ) or greater, are tested according to the same test procedure. This procedure specifies a single recommended sound level to be met by both trucks and buses. The measurement method provides for the determination of the maximum A-weighted sound level output of a vehicle during a low speed acceleration passby (high engine speed, low vehicle speed) as measured in the free-field over a reflecting plane. Since medium trucks and buses tended to be quieter than heavy trucks under these conditions, the majority of the emphasis has been placed on research and development programs aimed at reducing heavy truck noise.

There may be some proprietory data which have been obtained by the bus industry but it appears doubtful that these data are sufficiently extensive to provide EPA with even a substantial fraction of the information needed for a comprehensive analysis of the economic costs and technical feasibility associated with a given regulation. Furthermore, it is evident that there are practically no data available upon which to base an evaluation of alternative bus noise measurement procedures or to establish correlations between the noise associated with various operational modes and the noise measured utilizing various test procedures.

Thus, it appears that EPA will have to generate a rather extensive physical data base and investigate alternative measurement procedures prior to formulation of the Notice of Proposed Rule Making.

$13 /$ Most buses sold in the United States today exhibit exterior A-weighted noise levels of $86 \mathrm{~dB}$ or less measured according to SAE J366b procedures. Typically, school buses are in the range 79-86 dB while intercity and intracity buses are in the range 84-86 dB. Maximum interior levels are typically 80-84 $\mathrm{dB}[5]$. 
In this section, the information discussed in Sections 2 through 7 of this report serves as the basis for an overview of bus noise measurement problems. Utilizing this information, potential noise measurement problems that could hinder the promulgation and/or enforcement of future noise regulations to control noise emission from buses are identified.

Prior to the establishment of an appropriate measurement procedure that can be utilized for determining the exterior and interior noise of buses, certain informational requirements must be satisfied. These include: (1) a product classification scheme, (2) typical usage data (normal use conditions and range) and the effects of operation and environment on noise levels, and (3) the effects of bus noise on people. Such data allows one to select, with confidence, the acoustic quantity to be measured, the operational mode of the vehicle, and the locations for microphones which need to be specified in the regulation. Test site specifications and instrumentation requirements also hinge on the availability of this fundamental information.

\subsection{Classification}

Some of the factors associated with establishment of bus classes have been discussed in Section 2. There are actually two major purposes for bus classification in conjunction with noise regulations.

1. In order to establish different measurement procedures, or variations of the same measurement procedure, for buses which have different operational characteristics or which exhibit important variations in their acoustical characteristics.

2. In order to set different noise limits on different categories of buses, either because they are used differently and thus affect people in different ways or because of economic cost and technological feasibility of noise control as applied to the various classes of buses.

At present, sufficient data to allow correlations between the classes of buses -- categorized by engine type, weight, carrying capacity, intended usage, etc. - and the resultant noise levels characteristic of each class over the range of normal operation do not exist.

\subsection{Relation of Physical Measures to Effects/Normal Use}

The test procedure established for bus exterior and interior noise measurements should be such that the measured noise levels are representative of typical operation and not necessarily maximum levels.

At least three types of measurements come to mind when one considers measurement procedures which will permit adequate assessment of the noise exposures of the several groups affected: 
Sideline "far-field" noise, representative of that which is radiated to listeners located back from the side of a road or highway in a rather open area.

Sideline "near-field" noise, representative of that which is heard by persons waiting at bus stops, by passing pedestrians and motorists and by those working or living very near the street.

Noise inside the bus, representative of that heard by the passengers and drivers. Sub-cases include windows opened or closed and bus operating in a free field over a reflecting plane or near a reflecting surface (i.e., building or other vehicle). All of these exposure conditions occur for various operational modes of the bus.

In general, products have a range of possible operational modes with the noise emission characteristics dependent on how they operate. The key to deciding upon the mode or modes of operation of a vehicle that should be specified for noise test purposes hinges on the knowledge of how the vehicle is "normally" operated. In order to determine "normal operation" a usage survey should be conducted. Such data do not presently exist for buses.

In selecting appropriate operating procedures for use in bus noise tests, it is important to consider which of the major noise sources -engine (including exhaust, intake and cooling system), transmission (including -- gear box, drive shaft and drive axle(s)) and tires -- are important during the several modes of operation of buses. For instance, the low speed, acceleration test specified in SAE J366b includes engine noise and that part of transmission noise associated with the particular gear in which the vehicle is operated. It is assumed that the results of a $\mathrm{J} 366 \mathrm{~b}$ test are essentially unaffected by tire/road interaction noise. However, as the noise levels for sources other than tires are lowered, it is possible that tire noise may become a significant factor at the maximum speed allowed in a J366b test.

There is need to establish correlations between the noise emitted by buses in various operational modes and the noise emitted during simulated operations which may be much more convenient from a testing point of view; for example, a stationary run-up instead of a J366b passby.

\subsection{Quantity Measured}

The EPA "levels document" utilizes the equivalent A-weighted sound level as the appropriate quantity to use in characterizing noise exposure. Thus, it would be desirable if the quantity (or quantities) measured in a regulation on a specific noise source, e.g., a bus, could be easily and directly related to the contribution which the source makes to the equivalent $A$-weighted sound level for typical listeners. To the extent that a bus behaves like an acoustic monopole -- with uniform sound radiation in all directions - - it makes sense to measure the maximum 
A-weighted sound level at a particular microphone location during a vehicle passby. This measure of source strength can then be used to estimate the contribution which that source makes to the equivalent sound level at some other location. Data obtained on trucks and automobiles indicate that the sound level 50 feet $(15.2 \mathrm{~m})$ to the side of the vehicle centerline can be used fairly reliably to predict noise levels further from the vehicle. One can infer that this would also be the case for buses.

Conversely, it is highly questionable as to whether or not the maximum noise level at 50 feet $(15.2 \mathrm{~m})$ can be used to infer the contribution which a bus passby makes to the equivalent sound level at distances much closer to the bus -- distances which correspond to passengers at bus stops and other pedestrians. The lack of adequate correlation which has been observed (for trucks) between maximum noise levels at 50 feet $(15.2 \mathrm{~m})$ and 25 feet $(7.6 \mathrm{~m})$ makes it unlikely that adequate correlation with 50 foot $(15.2 \mathrm{~m}$ ) data will be observed for distances still closer to a bus.

In order to ascertain the contribution which buses make to the "reverberant level" in city streets with tall buildings on either side, it is necessary to consider whether or not the noise emission from buses is highly directional. If so, it might be necessary to measure the noise level in several directions from the bus.

Hopefully adequate correlations can be established to enable collapsing the number of measurement positions to a very few. However, it seems evident that a comprehensive experimental program is needed to guide and justify such simplification.

Since it is probable that new types of busesyill be developed in the near future, either through the Transbus Program or through private enterprise which use different types of power plants (such as a gas turbine engine) from those in current buses, it is necessary to address the question of whether the A-weighted sound level is an adequate metric for other than gasoline or diesel powered buses. For instance, what provisions, if any, should be made to account for different spectral characteristics, the presence of discrete pure tones and/or impulsive components?

\subsection{Acoustic Environment}

There appears to be general agreement that the noise emission from motor vehicles should be measured in a free field over a reflecting plane. If a 50 foot $(15.2 \mathrm{~m})$ measurement distance is utilized, a rather large open area is needed plus a roadway of sufficient length to accomodate the specified operational mode(s) of the vehicle.

Although considerable uniformity of testing has been achieved by the $\mathrm{SAE}$ and ISO in defining standard noise measurement procedures, there

14/The Transbus Program, sponsored by the U. S. Department of Transportation/ Urban Mass Transit Administration (UMTA), has as its objective the development of a totally new concept bus design by 1977. This program is discussed further in Appendix $\mathrm{C}$. 
remains a small but important variation between noise measurements made at different sites, or at different times at the same site. Experience to date with measurement of motor vehicle noise at 25 to 50 foot ( 7.6 to 15.2 m) distances, for typical microphone heights, indicates that the levels measured are sensitive to the characteristics of the surrounding ambient (air temperature, humidity, atmospheric pressure), to the characteristics of the reflecting plane (acoustic impedance, flatness), to temperature gradients above the plane (which depend on present and past air temperatures, sunlight, and wind velocities as well as the emittance and absorptance of the reflecting plane), and to atmospheric inhomogeneities (wind velocity and local turbulance). All of these factors influence the generation of noise by the propulsion system and associated auxiliary equipment, the radiation from the source into the surrounding atmosphere and/or the propagation from the immediate vicinity of the vehicle to the measurement location.

Since these factors influence reliable measurements of many of the sources which EPA is, or will be, regulating, there is a need for the various environmental and site effects to be systematically investigated so that: (1) noise measurements taken at a given site can be corrected to standard environmental conditions, (2) noise measurements taken at different sites under the same environmental conditions can be correlated and, therefore, (3) noise measurements taken at different sites under any environmental conditions can be correlated. If correction factors are not feasible then there is a need for a site calibration procedure and/or definition of limiting test conditions.

One must also be concerned with the environment inside a bus. The volume of the bus interior, the sound absorption of the walls, floor and ceiling as well as the interior furnishings, and the location of both the noise sources and the receivers must be carefully evaluated.

These are some of the factors which should be addressed. In general, these are factors over which one has little or no control.

\subsection{Instrumentation}

The instrumentation section of the regulation should require equipment meeting the Type 1 requirements of American National Standard Specifications for Sound Level Meters, S1.4-1971[11]. In addition, pertinent sections of American National Standard Methods for the Measurement of Sound Pressure Levels, S1.13-1971[15] should be incorporated. For instruments for which standards do not exist, or where existing standards are not sufficient, the regulation should include specific criteria for evaluating the performance of such devices. For example, a critical deficiency in existing standards is that the response of instrumentation to transient signals, e.g., vehicle passbys, is not well defined.

It is important to state clearly in the regulation the allowable toierances for frequency response, environmental effects, harmonic distortion, etc., which the instruments are required to meet. These 
specifications should be applied not only to specific components of the system but to the overall system as well. The overall system measurement error should not be degraded below that allowed for direct measurements regardless of the instrumentation configuration.

In addition, overall system calibration should be required at frequent stipulated intervals. The fact that each component of a system appears satisfactory does not ensure that the system performance will be acceptable.

\subsection{Alternative Test Procedures}

It is not seriously suggested that a bus noise regulation should explicitly require measurements corresponding to all possible exposure conditions coupled with all possible bus operational modes. However, it is important to consider the prevalance of each condition, perhaps in terms of its contribution to $\mathrm{L}_{\text {eg }}$ or $\mathrm{L}_{\mathrm{dn}}$, when evaluating the effects of bus noise on the populace. If several exposure conditions are found to be important, hopefully correlations can be developed which will enable collapsing the several cases into one or two measurements.

Because of the space, weather and time constraints associated with the existing low speed acceleration test procedures, it seems appropriate to investigate alternative procedures which would be simpler to perform yet correlatable with the "real world" situation. The Bureau of Motor Carrier Safety presently utilizes a stationary vehicle test procedure with the engine stabilized at its maximum rated or governed engine speed (high idle) as the basis for its regulation of truck and bus (interstate) interior cab noise. Present Federal noise certification procedures for interstate motor carriers also specify a stationary run-up test -- the engine is accelerated as rapidly as possible to its governed speed at wide open throttle (transmission in neutral). One of the main difficulties with stationary test procedures is the fact that noise associated with the gear train is not evaluated. Also, stationary procedures such as the stationary run-up test are limited in their applicability -- in this case the test can only be utilized on vehicles with governed engines. Although stationary tests probably take less time o perform and require less space (smaller test sites), all of the weather constraints which limit testing when the passby method is utilized would also be a problem with the stationary test.

Since the weather is a major limiting factor for all outdoor tests, it would seem logical to investigate the feasibility of indoor testing. If indoor testing were to be chosen as part of a standard or regulation, a testing facility would have to be specified in great detail and identical facilities would have to be constructed by each manufacturer -- small or large. It would appear to be prohibitively expensive to construct a facility to allow for 15.2 meters measurements; yet, measurements any closer than 15.2 meters would be questionable without extensive research to provide insight into the near field/far field effects and to establish the correlation between the results obtained according to such procedures with 
what the community experiences when a bus passes by. Also, the practical problem of removing the heat and exhaust fumes from the operating vehicle would have to be dealt with.

Any alternative procedures will have pros and cons associated with them; but they have almost no data base or experience base to back them up. Much research would be necessary before such procedures could be utilized as a measurement methodology for regulating the exterior or interior noise of buses.

9. Appendix A. A Discussion of Truck Subsource Noise $15 /$

\section{- Engine (mechanical)}

The engine and transmission form a complex acoustical system composed of a large number of sources, the most important of which result from the increase in pressure within the cylinder during combustion of the fuel. This rapid rise of cylinder pressure excites mechanical vibrations in the engine structure. Some of this vibrational energy is subsequently radiated into the atmosphere as acoustic energy. The gas forces are also transmitted through the piston and crank mechanism to the main bearings and hence excite flexible or mobile structures coupled to the crankshaft. Most of the noise generated by these mechanisms is radiated by the crankcase, oil pan, clutch housing and valve covers. The noise level produced by both gasoline and diesel engines depends upon engine size, speed and load. The noise level depends more on engine speed than on size, so that for a given horsepower, the quieter engines are associated with a larger displacement and slower engine speed. In practice there is a significant range in engine (mechanical) noise levels for a given engine size. Calculating the effect of engine noise on the overall vehicle noise level is difficult because the noise produced by a given engine depends upon the way in which it is mounted so that the level varies with the type of bus in which it is installed.

Gasoline engines initiate combustion with a flame which smoothly spreads throughout the cylinder until the fuel-air mixture is burned. Diesel engines, on the other hand, rely on much higher compression ratios to produce spontaneous combustion which rapidly oxidizes the fuel. This causes a more rapid change in pressure in the cylinder which in turn results in increased engine vibration and hence higher noise levels.

The primary combustion forces occur at the relatively low fundamental firing frequencies but the structure responds to the higher harmonics as well. Fuel injection equipment, pistons, valve train, gearing and accessories, all integral with or attached to the engine frame, contribute at various frequencies to deflect or vibrate the engine structure.

$15 /$

The material in this appendix was mainly derived from Wyle Laboratory reports to EPA $[5,17]$ on transportation noise and a cost-effectiveness study of major sources of bus noise and from material presented in the SAE Twentieth L. Ray Buckendale Lecture on truck noise control[18]. 
The engine itself contains several areas which vibrate and radiate noise. The blocks of $\mathrm{V}$ engines act as tuning forks while in-line engine blocks vibrate as beams. The motion of these relatively thin case block surfaces as well as sheet-metal components such as the oil pan, rocker arm cover, oil sumps, etc., which are attached to the vibrating structure, all increase the noise radiated to the atmosphere.

The character of the combustion forces can be changed advantageously by turbocharging. Turbocharging, which increases the pressure of the inlet air above atmospheric pressure, reduces the combustion force impact by making the pressure rise more gradual; thus, decreasing the noise radiated. Sheetmetal parts may be vibration isolated from the movement of the engine by use of soft gaskets and rubber washers at the mounting bolts. Engine covers using high density barrier materials lined with absorbent materials are the most effective way of reaucing engine noise but have the disacivantages of reduced accessibility to the engine, reduced cooling eificiency, added tieight, and potential fire hazards due to leaking oil being absorbed by the acoustical liners (which also destroys the noise absorption characteristics). Shielding under the engine can be effective in blocking the reflected path of noise from the engine to the receiver by way of a paved surface.

\section{- Exhaust System Iioise}

Exhaust noise is generated by the rapid release of high pressure combustion gases when the exheust valve opens. In adition to the discharge noise -- noise radiated to the atmosphere at the tail pipe outlet -- this rapid release of pressure excites oscillations of the muffler shell and exhaust and tail pipe surfaces which are radiated in the atmosphere as noise. Transmission loss through the pipes and flexible connections and gas leaks are aditional noise sources within the exhaust system. In the past, the outlet noise has overshadowed the other exhaust system sources; however, as the outlet noise is reduced by use of improved mufflers, the pipe anc shell noise become more significant contributors.

The primary Irequency components of exhaust noise are dependent upon engine speed, number of cylinders, exhaust system configuration (single or dual exhausts) and whether the engine is a 2-cycle or 4-cycle engine. Its amplitude is dependent upon ignition timing, throttle setting and engine load (pressure in the cylinder when the valve opens).

Uufflers or resonators are typically utilized to control exhaust discharge noise. The performance of these devices is very dependent upon other acoustic elements within the system such as the engine and the length and diameter of both the exhaust and tail pipes. In adition to providing effective noise reduction, mufflers must be designed to produce a tolerable back pressure on the engine.

Wuffler shell noise and pipe-radiated noise are similar in nature. General approaches to pipe and shell noise reduction include reducing the 
distance between the muffler and the manifold by utilizing a shorter exhaust pipe, by concealing pipes with shielding or by routing the pipes behind other bus components, or by utilizing damping materials to reduce muffler and pipe vibration.

Noise also can be produced by engine brakes which, when in use essentially convert a power producing diesel engine into a power absorbing air compressor. This is accomplished through a master-slave piston arrangement which opens cylinder exhaust valves near the top of the normal compression stroke releasing the compressed air charge to the exhaust manifold. The blowdown of compressed air to atmospheric pressure prevents the return of energy to the engine piston on the expansion stroke, the effect being a net energy loss since the work done in compressing the cylinder charge is not returned during the expansion process. Since the diesel engine is turned over by the driving wheels of a vehicle descending a hill through the vehicle drive line and transmission, application of the engine brake retards the "free-wheeling" effect of the driving wheels and a braking action results. Advantages such as elimination of continual braking with the vehicle service brakes, ability to maintain engine operating temperatures on down grades, increased life of brake components and tires and added safety make this device a popular option in certain geographical areas. The noise produced by the blowdown of the compressed air to the atmosphere is generally controlled by making improvements to the engine brake itself or through the use of improved mufflers.

\section{- Cooling System Noise}

The fan is the predominant noise source in the cooling system. The fan, as an air moving device, creates lift forces to cause air motion. Since the lift force is the result of a pressure difference across the fan blade, the lift force actually rotates with the blades and, relative to a fixed point, fluctuates each time a blade passes setting up pulsations in the surrounding area. Such pulsations result in the generation of a fundamental tone, associated with the blade passage frequency, and higher order harmonics. Non-uniform air flow across the face of the fan (due to improper distribution of the air from the radiator) and obstructions near the fan such as hoses, alternators, etc., which create air flow irregularities intensify the fan noise problem. In addition, random pressure fluctuations, resulting in broadband noise, are caused by the non-coherent shedding of vortices from trailing edges of the blades and by turbulence generated upstream of the fan arising from the passage of the cooling air over the tube and fin surfaces of the radiator.

An obvious approach to rèduce cooling system noise is to increase cooling efficiency and thus allow for decreased fan speed. A larger fan turning at a slower speed which can be swept over a larger radiator core area with possibly a lower tip speed has obvious advantages. Fan shrouds can also be used to prevent air recirculation through the fan, thereby ensuring that all of the air pumped by the fan has passed through the radiator to provide cooling. The clearance between the outer edges of the fun blades and the shroud (tip clearance) can also be a major factor. To 
ensure optimum noise reduction the tip clearance should be as small as practical.

Cooling systems are designed for "worst case" situations which seldom occur. In actual service conditions, the heat load is such that full fan speed is not required much of the time. The critical condition for buses from a cooling demand standpoint, is when the vehicle is fully loaded and is ascending a long grade at full engine power but low road speed. Fans operating at full speed are necessary during this period to provide necessary cooling in the absence of the ram air effect. Additionally, fans are usually operating when the vehicle is idling; however, the fan is not operating at its maximum rpm and therefore the noise generation is not significant. At fan speeds of less than $1600 \mathrm{rpm}$ the fan noise is sufficiently less than the fan noise at governed engine speed (usually about 2100 rpm) and therefore the contribution to the overall noise level of the vehicle is not significant.

On the basis of the previous discussion, it appears that the obvious approach to the fan noise problem would be the utilization of a demand fan in place of a direct drive fan. Clutched fan drives -- either on-off or modulating -- do exist on the market today (in limited quantities); however, they are not widely utilized in buses at the present time. Such fans are thermostatically controlled and operate only when needed. On-off fans are either full-on or full-off, in other words, when cooling is needed the fan comes full-on and remains on until the cooling demand has been satisfied. The speed of the modulating fan varies to compensate for the heat rejection demands of the engine and seldom is at "full-on" condition.

Present limited data[19,20] utilizing trucks equipped with demand fans indicate that actual fan "on time" is on the order of a few percent of engine on time under actual over-the-road conditions. Such fan clutches are not prevalent at the present time; however, the promulgation of new noise regulations which accept the higher noise levels during that small percentage of the time when the heat rejection demand on the cooling system is high in order to achieve lower noise emissions the remainder of the time should alter this situation.

\section{- Air Intake Noise}

Engine air-intake noise is produced by the intake pulsations on 4-cycle naturally aspirated engines, by blower blades on a turbocharged engine, and by blower lobe passage disturbances on pressure scavenged 2-cycle engines.

Intake systems are similar to exhaust systems in that the components and problems are much the same; however, each intake system must be treated individually since both the frequency and amplitude of intake noise varies with engine type. Low frequency intake noise is generally controlled by the use of properly designed and located large volume air-cleaners matched to the intake pipe. Tuned silencers are usually required to reduce the 
high frequency components of intake noise. Location of the air intake openings, e.g., toward the front of the vehicle rather than to the side, can also be effective in controlling intake noise as observed by a bystander along the road.

At present, the air intake system is not a major contributor to overall bus noise levels for most manufacturers; however, as overall noise levels are reduced, the intake system will have to be re-evaluated.

\section{- Tire-Road Interaction Noise}

The physical mechanisms of the production of noise by the tire-road interaction process are not well understood. The general consensus is that air pumping (entrapment and release of air from the tire tread cavities) and vibration of the tire carcass are the major mechanisms contributing to the generation and radiation of acoustic energy. However, the effect of tread design (rib, crossbar), effect of road surface, effect of wear, and the effect of load on the noise levels produced are known. The existing data do not provide the basis for the design of quieter tires.

Bus tread designs for highway usage can be classified basically into two categories -- rib and cross-bar. Rib type tires, with the major tread elements oriented in the circumferential direction, possess characteristics that are suitable for all wheel locations. These tires are noted for their lateral traction and uniform wear characteristics. Cross-bar tires are used primarily on the drive axles. This design, with the major tread elements oriented in the lateral direction, gives maximum driving traction, provides a much more rigid tread structure, and provides greater original design tread depth. The final choice of which type of tire is utilized depends on many factors, some of which include the original cost of the tire, a concept of the safety provided by a given tire and a knowledge of the company's policy on retreading. The true cost of a tire (cost/mile) is dependent, for instance, on the number of times a carcass -- be it rib or cross-bar tread design originally - - will be retreaded. Many bus operators prefer not to use recapped tires and they buy special tires that come with a thick layer of rubber under the original tread. After the original tread has been worn down, a new tread may be grooved into this layer and the tire reused.

Cross-bar tires, as a generic group, are noisier than the rib-tread tires. The difference between the quietest cross-bar tire and the noisiest rib tire is typically 4-8 dB. Also of interest is the fact that only a 1 to $2 \mathrm{~dB}$ decrease is observed between the quietest rib tire and a completely smooth tread. Therefore, a breakthrough in basic tire design appears to be needed before tires exhibiting significantly lower noise levels could be manufactured. Such a breakthrough does not appear to be imminent.

Road surface conditions do influence tire noise levels; however, the effect depends on the tire type, for instance, cross-bar tires generally 
produce higher noise levels when running on a rougher surface but in any case the influence is not very significant. Rib tires tend to get noisier as the surface gets rougher. It should be noted at this point that no method now exists for quartitatj.vely characterizing the surface roughness or texture of pavements typical on today's roads. Until the surface texture can be physically characterized, little can be known about the effect of surface roughness on the generation of tire noise.

It is known that sound levels rise with increasing speed for all tires, but at slightly different rates. Empirically, tires are characterized by an increase of 6 to $12 \mathrm{~dB}$ for a doubling of vehicle speed in the range of 30 to $60 \mathrm{mph}(48.3$ to $96.5 \mathrm{~km} / \mathrm{hr})$. Theoretical considerations supporting relationships in which sound level increases as either $30 \log _{10} \mathrm{~V}$ or $40 \log _{10} \mathrm{~V}$, where V is speed, have been developed. This is within the range of the empirical data.

Load is also an important parameter. The increase in sound level that exists between the unloaded and loaded condition is significant for cross-bar tires. As the load is increased for tread designs of the cross-bar type, more of the tire load is carried on the outer sections of the tread where the most drastic interruptions in tread pattern exist.

Rib tires are relatively unaffected by load. In this case the rib pattern is the same across the width of the tire and, hence, it is not important how much load is carried on the outer edges of the tire.

Tread wear is another variable that can greatly affect the sound level generated by tires. Tire noise generally increases between the new and half-worn states and depending on the tire type either increases or decreases with additional wear. It appears that the factor controlling the change in noise level with wear is the change in tread curvature.

Other factors -- inflation pressure, tire temperature, etc. -- also can influence tire noise but their effect is not thought to be as great as those parameters discussed above. 
1. Introduction-This SAE Standard establishes the test procedure cmurnment, and instruntentation for determining the inaxinum ex terior sound level for highway unotor trucks, truck tractors, and buses. the Appendix contains the recommendations of SAE for maximum sound level.

2. Instrumentation-The following instrumentation shall be used, where applicable, for the measurement required:

2.1 A sound level meter which mects the Type I requilenents of ANSI SI 4-1971. Specification for Sound Level Meters.

2.1.1 As an alternative to making direct measurements using a sound level meter, a microphone or sound level meter may be used with a Inagnetic tape recorder and/or a graphic level recorder or indicating meter, providing the system meets the requirements of SAE J184.

2.2 A sound level calibrator (sce paragraph 5.2 .3 ).

2.3 An engine-speed tachometer (see paragraph 5.1.1)

3. Test Site

3.1 A suitable test site shall consist of a level open space free of large reflecting surfaces, such as parked schicles, signtoards, huildings, or hillsides, lucated within $100 \mathrm{ft}(30 \mathrm{~m})$ of either the vchicle path or the microphone. See Fig. I

3.2 The microphone shall be located $50 \mathrm{ft}(15 \mathrm{~m})$ from the center line of the vehicle path and $4 \mathrm{ft}(1.2 \mathrm{~m})$ above the ground plane. Tlue normal to the vehicle path from the microphone shall establish the microphone point on the vehicle path.

3.3 An acceleration point shall be established on the vehicle path $50 \mathrm{ft}(15 \mathrm{~m})$ before the microphone point.

9.4 An end point shall be established on the vehicle path $100 \mathrm{ft}$ $(90 \mathrm{in})$ from the acceleration point and $50 \mathrm{ft}(15 \mathrm{~m})$ from the micro phone point.

9.5 The end zonc is the last $40 \mathrm{ft}(12 \mathrm{n})$ of vehicle path prior to the end point

3.6 The measurement area shall be the triangular area formed by the acteleration point, the end point, aud the microphone location.

3.7 The reference point on the vehicle, to indicate when the ichicle is at any of the points on the ichicle path, shall he the front of the vehicle except as follows:

3.7.1 If the horizontal distance from the front of the vehicle to the exhaust outlet is more than 200 in $(5080 \mathrm{~mm})$, tests shall be run using both the front and tear of the vehicle as reference points.

3.7 .2 If the engine is located rearward to the center of the chassis. the rear of the vehicle shall be used as the reference point

3.8 During measurement, the surface of the ground within the ineasurement area shall be free fron powdery snow, long grass. loose soil, and ashes.

3.9 Because bystanders have an appreciable influence on meter re sponse when they are in the vicinity of the vehicle or microphone, not more than one person, other than the observer reading the meter, shall be within $50 \mathrm{ft}(15 \mathrm{~m})$ of the velicle path or instrument, and that person shall be directly behind the observer reading the meter, on a line through the microphone and the observer

3.10 The ambient sound level (including wind effects) coming from sources other than the vehicle being measured shall be at least $10 \mathrm{~dB}(\mathrm{~A})$ Jower than the level of the tested vehicle.

3.11 The vehicle path shall be relatively smooth, dry concrete or isphalt, frec of extraneous material such as gravel.

4. Procedure

4.I Vehicle Operation-Full throttle acceleration and closed throt lle deceleration tesis are to be used $A$ beginning engine speed and proper gear ratio must be desermined for use during measurements.

4.I.I Select the highest rear axle and/or transmission gear ("highest gear" is used in the usual sense; "1 is sy nonmous to the lowest numer ical ratuo) and an initial vehicle speed such that at wide-open throttle the vehicle will accelerate from the acceleration point:

(a) Starting at no more than two thirds $(66 \%)$ of maximuin rated or of governed engine speed.

(b) Reaching maximum rated or governed engine speed within the end zone. point

(c) Without exceeding $35 \mathrm{mph}(56 \mathrm{~km} / \mathrm{h})$ before reaching the end

4.1.1.1 Should maximum rated or governed rpm be attained before reaching the end zone, decrease the approach $\mathrm{rpm}$ in $100 \mathrm{rpm}$ incre ments until inaxinum rated or governed rpm is attained within the cud zone.

4.1.1.2 Should maxinun rated or guverued $\mathrm{rpm}$ not be attained until beyond the end zone. select the bent lower gear until maximum tated or goverued rpin is attuned within the encl zone

4.1.1.5 Should the lowest gear still result in reaching maxinum rated or governed rpm letond the permissible end zone. unload the selaxle and or increase the approach rpm in $100 \mathrm{rpm}$ increments until the maximum sated or governel rpm is reached within the end zone

4.1.2 For the acceleration test, approach the acceleration point using the engine speed and gear ratio selected in paragraph 4.1.1 and at the acceleration point rapidls establish wide-open throttle. The vehicle ref erence shall be as indicated in paragraph 3.7. Acceleration shall con tinue until maxinum rated or gorcuned engine specd is reached.

4.1.3 Wheel slip which affects maximum sound level must be avoided

4.1.4 For the deceleration test, approach the microphone point at maximum rated or governed engine speed in the gear selected for the acceleration test. At the miciophone point, cluse tlie throttle and allow the sehicle to decelerate to one half of inaimum rated or of gov erned engine speed. The vehicle reference shall be as indicated in paragraph 3.7. If the vehicle is equipped with an exhaust brake, this deceleration test is to be repeated with the brake full on immediately following closing of the throttle.

4.2 Mcasurements

4.2.1 The meter shall be set for "fast" response and the A.weighted 11cin'ork

4.2.2 The meter shall be observed during the period while the vehicle is acceleriting or deceleranng. $7 \mathrm{l}$ c applicable reading shall be the highest sound lesel obtained for the run. The observer is cautioned to rerun the test if unrelated peaks should occur due to extraneous ambient noises. Readings shall he taken on both sides of the vehicle.

4.2.3 The sound level for each side of the vehicle shall be the average of the two highest readings which are within $2 \mathrm{~dB}$ of each other Report the sound level for the side of the vehicle with the lighest reallings.

5. General Comments-Measurements slatl be made only when wind velocity is below $12 \mathrm{mph}(19 \mathrm{~km} / \mathrm{h})$.

$5.1 \mathrm{It}$ is strongly recommended that technically trained personne select the equipment and that tests are conducted only by qualified per sons trained in the current techriques of sound measurement.

5.2 l'roper usage of all test instrumentation is essential to obtain valid measurements. Operating manuals or other literature furnished by the instrument manufacturer sliould be referred to for both recom mended operation of the instrument and precautions to be observed. Specific items to be considered are:

5.2.1 The effects of ambient weather conditions on the performance

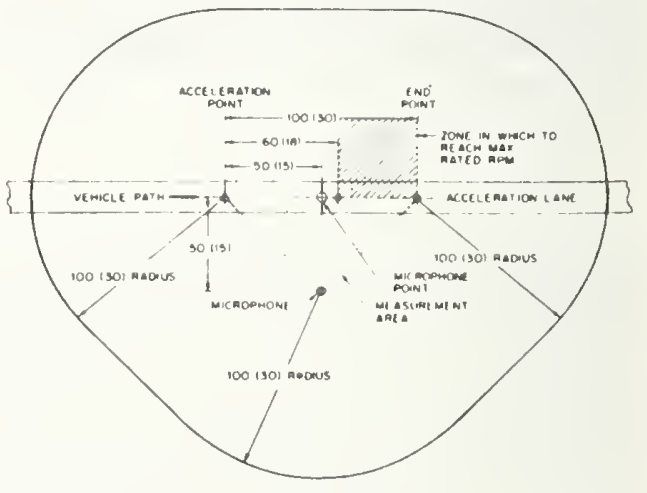

FIG. I-MINIMUM UNIDIRECTIONAL, TEST SITE (SEE PARA GRAPH 3.1) 
of all instuments (for ixample, temperature, humidity, and barometric pressure).

5.2.2 Proper signal lesels, teuminating impedances, and cable length on multi.instrument measurement systems.

5.2.3 Proper acoustical calibration procedure, to include the infiuence of extension cables, etc. Field calibration shall be made im. mediately before and after each test sequence. Internal calibration means is acceptable for field use, provided that external calibration is accumplished immediately before or after field use.

5.3 Vehicles used for tests must not be operated in a manner such that the break-in procedure specified by the manufacturer is violated.

6. References-Suggested reference material is as follows:

ANSI S1.1-1960. Acoustical Terminology

ANSI S1.2-1967. Physical Measurement of Sound
ANSI S1.4-1971. Sperification for Sound level Meter

Applications for copies of these documents should be addressed to the American National Standards Institute, Inc., 1430 Broadway, New York. New York 10018.

\section{APPENDIX}

The SAE recommends that a maximum A.weighted sound level of $88 \mathrm{~dB}$ when measure in accordance with the test procedure described above be used as a reference in the design and development of heavy trucks and buses.

An additional $2 \mathrm{~dB}$ allowance over the sound level limit is recommended to provide for variations in test site, temperature gradient, test equipment, and inherent differences in nominally identlcal vehicles. 


\section{CALIFORNIA HIGHWAY PATROL NOISE MEASUREMENT PROCEDURE}

EDITED FOR NEW VEHICLES

\section{ORDER ADOPTING, AMENDING, OR REPEALING REGULATIONS OF THE DEPARTMENT OF THE CALIFORNIA HIGHWAY PATROL}

After proceedings had in accordance with the provisions of the Administrative Procedure Act (Gor. Code, Title 2, Div. 3, Part 1, Chapter 4.5) and pursuant to the authority vested by Section 2402 of the Vehicle Code, and to implement, interpret, or make specific Sections 23130 and 27160 of the Vehicle Code, the Department of the California Highway Patrol hereby adopts, amends, or repeals regulations in Chapter 2, Title 13, California Administrative Code, as follows:

\section{(1) Amends Article 10, Subchapter 4 to read:}

Article 10. Vehicle Noise Measurement

1040. Scope of Regulations. This article contains procedures implementing Section 23130 of the Vehicle Code which applies to the measurement of noise from motor vehicles and combinations of vehicles subject to registration when operated on a highway and Section 27160 of the Vehicle Code which applies to the measurement of noise from new motor vehicles offered for sale.

1041. Definitions. The following definitions shall apply wherever the terms are used in this article:

(a) First Gear. The "first gear" is the highest numerical gear ratio of the transmission which is commonly referred to as low gear.

(b) Maximum RPM. The "maximum $r p m$ " is the maximum governed engine speed, or if ungoverned, the rpm at maximum engine horsepower as determined by the engine manufacturer in accordance with the procedures in SAE J245, April 1971 .

(c) Vehicle Reference Point. The "vehicle reference point" is the location on the vehicle used to determine when the vehicle is at any of the points on the vehicle path. The vehicle reference point shall be the front of the vehicle unless such positinn is more than $16 \mathrm{ft}$ from the exhaust outlet, in which case both the front of the vehicle and the exhaust outlet shall be used as reference points.

1042. Personnel. Persons selected to conduct noise measurement testing or to measure noise level of vehicles operated on a highway shall have been trained and qualified in the techniques of sound measurement and the operation of scund measuring instruments.

1043. Instrumentation. Equipment used in making vehicle noise measurements shall be selected by technically trained personnel and shall meet 
the following requirements:

(a) Sound Level Meter. The sound level meter shall meet the requirements of ANSI Standard S1.4-1971 for Types 1, 2, or S2A.

(b) Sound Level Calibrator. The sound level calibrator shall calibrate the entire sound level meter with an acoustic calibrator of the coupler-type.

(c) Tachometer. A calibrated engine speed tachometer shall be used to determine when maximum rated $\mathrm{rpm}$ is attained in conducting the tests specified in Section 1046 of this code.

(d) Anemometer. An anemometer shall be used to measure the wind speed at the test site when conducting tests specified ir Section 1046 of this code.

1044. Noise Measurement Sites. Noise measurement sites shall be selected to meet location, ground condition, and roadway surface requirements in the following subsections (a) and (b):

(a) Measurement Sites for Venicles on the Highway.

(b) Measurement Sites for New Motor Vehicles. Sites for measuring noise from new motor vehicles to determine compliance with Section 27160 of the Vehicle Code shall meet the following conditions:

(1) Location. The location shall be a flat open space free of large vertical sound-reflecting surfaces such as signboards, buildings hillsides, or trees within 100 ft of the microphone and within $100 \mathrm{ft}$ of the centerline of the path of the vehicle from the point where the throttle is opened to the point where the throttle is closed.

(2) Ground Condition. The ground surface between the microphone and the path of the vehicle shall be asphalt or concrete free of powdery snow, 1 e soil, or ashes.

(3) Roadway Surface. The surface over which the vehicle travels shall be dry and relatively smooth concrete or asphalt pavement free of extraneous material.

1045. Microphone and Personnel Positions. The microphone for the sound level meter and the personnel involved in all types of vehicle noise measurements shall be positioned as follows:

(a) Microphone Location. The microphone shall be located $50 \pm 1$ ft from the centerline of the lane of travel of the vehicle at a height of $\overline{4} \pm 1 / 2 \mathrm{ft}$ above the plane of the roadway surface.

(b) Microphone Orientation. The microphone shall be oriented in relation to the source of the sound in accordarce with the instrument 
manufacturer's instructions. Where the instruction manual is vague or does not include adequate information, a specific recommendation shall be obtained from the manufacturer.

(c) Technician Location. The technician making direct readings of the meter shall be positioned in relation to the microphone in accordance with the instrument manufacturer's instructions. Where the instruction manual is vague or does not include adequate information, a specific recommendation shall be obtained from the manufacturer.

(d) Bystander Location. During noise measurements, bystanders shall remain at least 50 ft from the microphone and the vehicle being measured, except for a witness or trainee, who may be positioned beyond the technician on a line with the technician and the microphone.

1046. Operation of New Motor Vehicles. New motor vehicles tested to determine compliance with Section 2.7160 of the Vehicle Code shall be operated in confunction with any auxiliary equipment that would be in use while the vehicle is operated on the highway, including but not limited to cement mixers, refrigerator units, and garbage compactors.

(a) Heavy Trucks, Truck Tractors, and Buses.

(b) Iight Trucks, Truck Tractors, Buses, and Passenger Cars.

(c) Motorcycles. The test procedure for motorcycles shall be as follows :

(1) Test Area Irayout. The test area layout for motorcycles shall be the same as specified in subsection (b) ( 1 ) and Figure 3 for light trucks, truck tractors, buses, and passenger cars. (See next page.)

(2) Gear Selection. Motorcycles shall be operated in second gear. Vehicles which reach maximum rpm at less than $30 \mathrm{mph}$ or before a poirt $25 \mathrm{ft}$ berond the microphone point shall be operated in the next higher gear.

(3) Acceleration. The vehicle shall proceed along the test path at a constant approach speed which corre ponds either to an engine speed of $60 \%$ of maximum rpm or to $30 \mathrm{mph}$, whichever is lower. When the vehicle reference point reaches the acceleration point, the throttle shall be fully opened. The throttle shall be held open until the rear of the vehicle is approximately $100 \mathrm{ft}$ beyond the microphone or until the maximum rpm is obtained, at which point the throttle shall be gradually closed. Wheel slip shall be avoided during this test.

(4) Engine Temperature. The engine temperature shall be within normal operating range before each test run. 


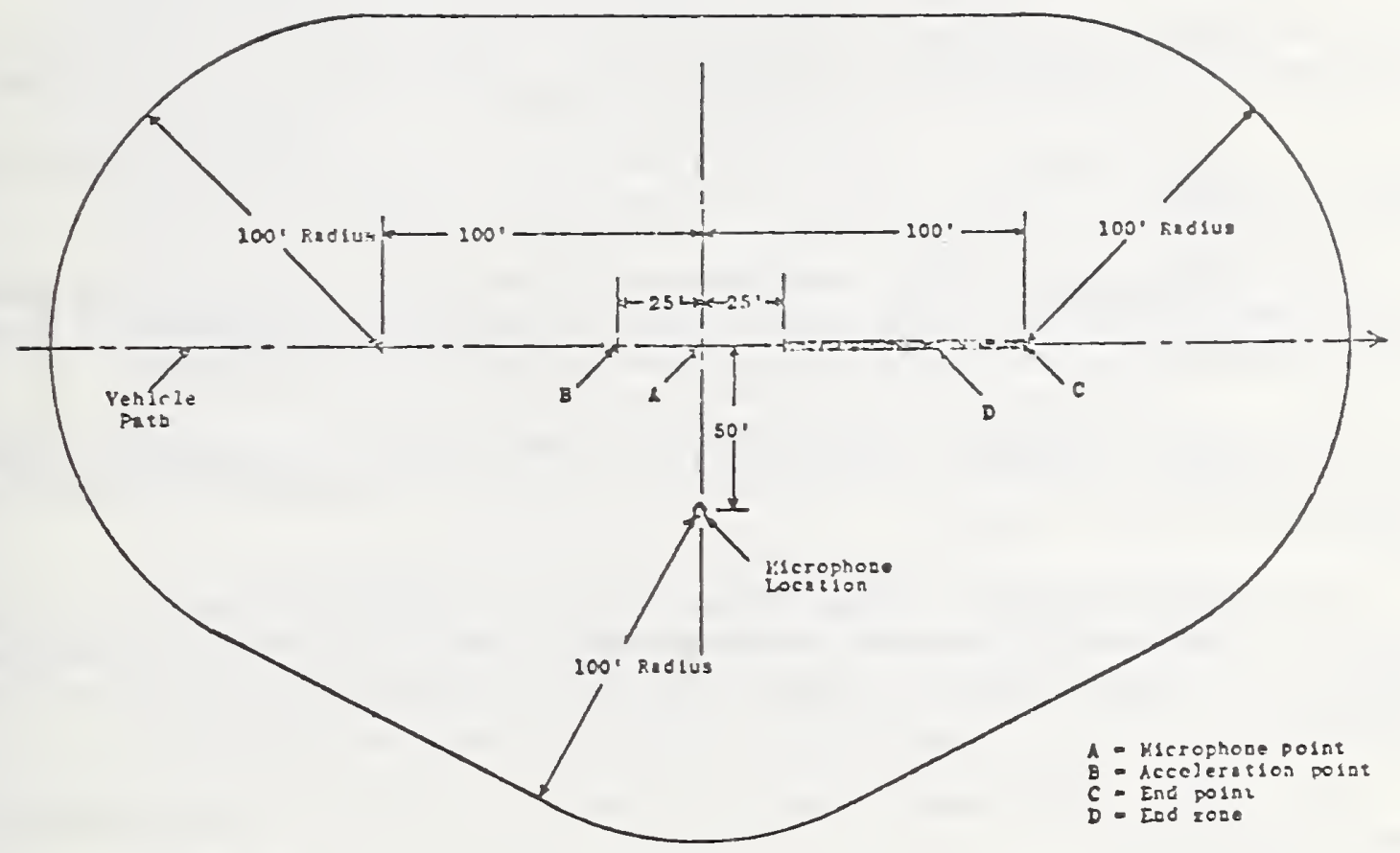

Test Area Iavout. The test area shall include a vehicle path of sufficient length for safe accelesaticn, deceleration, and stopping of the vehicle. The vehicle path (shown with only one directional approach in Figure 3 for purposes of clarification) shall be marked with the following zone and points:

(A) Microphone point - the location on the centerline of the vehicle path that is closest to the microphone.

(B) Acceleration point - a location 25 ft before the microphone point.

(c) End point - a location $100 \mathrm{ft}$ beyond the microphone point.

(D) End zone - the last 75-ft distance between the microphone point and the end point.

Figure 3. Test Area Layout for Iight Trucks, Truck Tractors, Buses, Passenger Cars and Motorcycles. 
(d) Deceleration. Tests during deceleration shall be conducted when deceleration noise appears excessive. The vehicle shall approach the end point from the reverse direction a maximur rpm in the same gear selected for the tests during acceleration. At the end point, the throttle shall be closed and the vehicle shall be allowed to decelerate to $1 / 2$ of maximum rpm.

1047. Meter Operation. The sound level meter shall be operated in accordance with the instrument manufacturer's instructions and as follows:

(a) Meter Setting. The 1 -weighting network and the fast meter response shall be used.

(b) Calibration Check. An external calibration check shall be made before and after each period of use and at intervals not exceeding 2 hr when the instrument is used longer than a 2-hr period.

(c) Meter Reading. The reading recorded shall be the highest sound level obtained as the vehicle passes by, disregarding unrelated peaks due to extraneous ambient noises.

(d) Ambient Sound. Measurements shall be made only when the A-weighted ambient sound level, including wind effects, due tn all sources other than the vehicle being measured, is at least $10 \mathrm{~dB}(\mathrm{~A})$ lower than the sound level of the vehicle.

(e) Wind. Measurements shall be made only when the wind velocity is less than $12 \mathrm{mph}$.

1048. Vehicle Noise Level. The measured noise level of a vehicle shall be reported as follows:

(a) Vehicles on the Highway.

(b) New Motor Vehicles. The sound leve readings for determining compliance of new motor vehicles with Section 27160 of the Vehicle Code shall be obtained after sufficient preliminary runs to enable the test driver to become familiar with the operation of the vehicle and to stabilize engine operating conditions.

(1) At ieast four measurements shall be made from each side of the vehicle. When the exhaust outlet is more than $16 \mathrm{ft}$ from the driver's position, at least two runs in each direction shall be performed with each of the reference points described in section 1041 (c) of this code.

(2) The A-weighted sound level for each side of the vehicle shall be the average of the two highest readings on that side which are within $2 \mathrm{~dB}(\mathrm{~A})$ of each other. The noise level reported for the vehicle shall be the sound level of the loudest side. 


\section{Measurement of Noise Emitted by Vehicles $17 /$}

\section{SCOPE}

This ISO Recommendation describes methuds of determining the noise emitted by motor vehicles, these being intended to meet the requirements of simplicity as far as is consistent with reproducibility of results and realism in the operating conditions of the vehicle.

\subsection{Test conditions}

\section{GENERAL REQUIIREMENTS}

This ISO Recommendation is bascd primarily on a test with vehicles in motion, the ISO rcference tcst. It is generally recognized to be of primary importance that the measurements should relate to normal town driving conditions, thus including transmission noise etc. Measurements should also relate to vehicle conditions which give the highest noise level consistent with normal driving and which lead to reproducible noise emission. Therefore, an acceleration test at full throttle from a stated running condition is specified.

Recognizing. however, that different practices already exist, specifications of two other methods used are also given in the Appendix. These relate to:

(a) a test with stationary vehicles (see Appendix Al) and

(b) a test with vehicles in motion, under vehicle conditions which (in the case of certilin vehicles) are different from those in the ISO reference test (sec Appendix A2).

When either of these tests is used, the relation between the results and those obtained by the ISO reference test should be established for typical examples of the model concerned.

\subsection{Test site}

The test methods prescribed call for an acoustical environment which can only be obtained in an extensive open space. Such conditions can usually be provided

for type-approval measurements of vehicles,

for measurements at the manufacturing stage, and

for measurements at official testing stations.

It is desirable that spot checking of vehicles on the road should be made in a similar acoustical environment. If measurements have to be carried out on the road in an acoustical environment which does not fulfil the requirements statcd in this ISO Recommendation, it should be recognized that the results obtained may deviate appreciably from the results obtained using the specified conditions.

\subsection{Interpretation of results}

The results obtained by the methods specified give an objective mcasure of the noise emitted under the prescribed conditions of tcst. Owing, however, to the fact that the subjcctivc appraisal of the annoyance or noisiness of differcnt classes of motor vehicles is not simply related to the indications of a sound level metcr, it is recognized that the correct interpretation of results of the measurements in this ISO Recommendation may require different limits in he set for the corresnonding annoyance of different classes of vchicles. 
A high quality sound level meter should be used. The weighting network and meter time constant employed should be curve " $A$ " and "fast response" respectively, as specified in Recommendation No. 123 of the International Electrotechnical Commission for Sound Level Meters. A detailed technical description of the instrument used should be supplied.

Notes

1. The sound level measured using sound level meters having the microphone close to the instrument case may depend on the orientation of the instrument with respect to the sound source, as well as on the position of the observer making the measurement. The instructions given by the manufacturer concerning the orientation of the sound level meter with respect to the sound source and the observer should therefore be carefully followed.

2. If a wind shield is used for the microphone, it should be remembered that this may have an influence on the sensitivity of the sound level meter.

3. To ensure accurate measurements, it is recommended that before each series of measurements the amplification of the sound level meter be checked, using a standard noise source and adjusting as necessary.

4. It is recommended that the sound level meter and the standard noise source be calibrated periodically at a laboratory equipped with the necessary facilities for free-field calibration.

Any peak which is obviously out of character with the general sound level being read should be ignored.

\section{ACOUSTICAL ENVIRONMENT}

The test site should be such that hemispherical divergence exists to within $\pm 1 \mathrm{~dB}$.

Note.-A suitable test site, which could be considered ideal for the purpose of the measurements, would consist of an open space of some $50 \mathrm{~m}$ radius, of which the central $20 \mathrm{~m}$, for example, would consist of concrete, asphalt or similar hard material.

In practice, departure from the so-called "ideal " conditions arises from four main causes:

(a) sound absorption by the surface of the ground;

(b) reflections from objects, such as buildings, and trees, or from persons;

(c) ground which is not level or of uniform slope over a sufficient area;

(d) wind.

It is impracticable to specify in detail the effect produced by each of these influences. It is considered important, however, that the surface of the ground within the measurement area be free from powdery snow, long grass, loose soil or ashes.

To minimise the effect of reflections, it is further recommended that the sum of the angles subtended at the position of the test vehicle by surrounding buildings within $50 \mathrm{~m}$ radius should not exceed $90^{\circ}$ and that there be no substantial obstructions within a radius of $25 \mathrm{~m}$ from the vehicle.

Acoustical focussing effects and sites between parallel walls should be avoided.

Wherever possible, the level of ambient noise (including wind noise and-for stationary testsroller stand and tyre noise) should be such that the reading produced on the meter is at least $10 \mathrm{~dB}$ below that produced by the test vehicle. In other cases, the prevailing noise level should be stated in terms of the reading of the meter.

NOTE.-Care should be taken that gusts of wind do not distort the results of the measurements.

The presence of bystanders may have an appreciable influence on the meter reading, if such persons are in the vicinity of the vehicle or the microphone. No person other than the observer reading the meter should therefore remain in the neighbourhood of the vehicle or the microphone.

Note.-Suitable conditions exist, if bystanders are at a distance from the vehicle which is at least twice the distance from vehicle to microphone. 


\section{MEASUREMENTS WITH VEHICLES IN MOTION}

\section{S.1 Testing ground}

The testing ground should be substantially level, and its surface texture such that it does not cause excessive tyre noise.

\subsection{Measuring positions}

The distance from the measuring positions to the reference line $C C$ (Fig. 1) on the road should be $7.5 \mathrm{~m}$. The path of the centre line of the vehicle should follow as closely as possible the line $C C$.

The microphone should be located $1.2 \mathrm{~m}$ above the ground level.

\subsection{Number of measurements}

At least two measurements should be made on each side of the vehicle as it passes the measuring positions.

NoTe.-It is recommended that preliminary measurements be made for the purpose of adjustment. Such preliminary measurements need not be included in the final resuit.

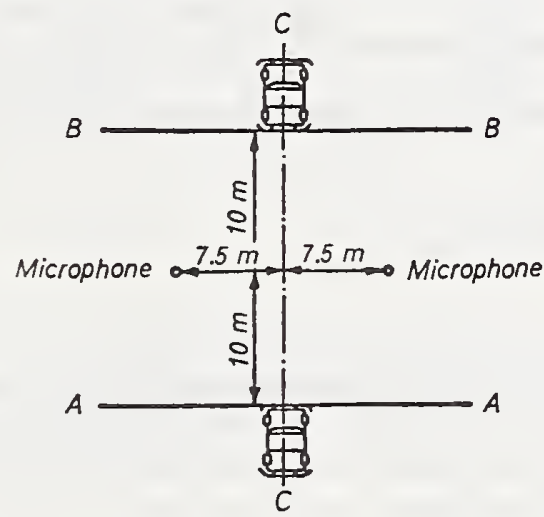

Fig. 1. - Measuring positions for measurement with vehicles in motion

\subsection{Test procedure}

\subsubsection{General conditions}

The vehicle approaches the line $A A$ in the appropriate conditions specified below:

When the front of the vehicle reaches the position, in relation to the microphone, shown as $A A$ in Figure 1, the throttle is fully opened as rapidly as practicable and held there until the rear of the vehicle reaches position $B B$ in Figure 1, when the throttle is closed as rapidly as possible.

Trailers, including the trailer portion of articulated vehicles, are ignored when considering the crossing of line $B B$.

NoTE.-If the vehicle is specially constructed with equipment (such as concrete mixers, compressors, pumps, etc.), which is used whilst the vehicle is in normal service on the road, this equipment should also be operating during the test. 


\subsubsection{Particular conditions}

5.4.2.1 Vehicle With no Grak-Box. The vehicle should approach the line $A A$ at a stcady speed corresponding

either to an cnginc speed of three quarters of the spccd at which the engine develops its maximum power.

or to three quarters of the maximum engine speed permitted by the governor, or to $50 \mathrm{~km} / \mathrm{h}$,

whichever is the lowest.

5.4.2.2 Vehicle with a manunlly operated gear-box. If the vehicle is fitted with a two-, three-, or four-speed gear box, the second gear should be used. If the vehicle has more than four speeds, the third gear should be used. Auxiliary step-up ratios (" overdrive") should not be engaged. If the vehicle is fitted with an auxiliary reduction gear box, this should be used with the drivc allowing the highest vehicle speed.

The vehicle should approach the line $A A$ at a steady spced corresponding

either to an engine speed of three quarters of the speed at which the engine develops its maximum power,

or to three quarters of the engine speed permitted by the governor, or to $50 \mathrm{~km} / \mathrm{h}$,

whichever is the lowest.

5.4.2.3 Vehicle with an automatic gear-Box. The vehicle should approach the line $A A$ at a steady speed of $50 \mathrm{~km} / \mathrm{h}$ or at three quarters of its maximum speed, whichever is the lower. Where alternative forward drive positions are available, that position which results in the highest mean acceleration of the vehicle between lines $A A$ and $B B$ should be selected.

The selector position which is used only for engine braking, parking or similar slow manæuvres of the vehicle should bc excluded.

5.4.2.4 Agricultural, tRACTORS, SELF-PROPELled AGRICULTURAL MACHINES AND MOTOR CULtivators. The vehicle should approach the line $A A$ at a steady speed of three quarters of the maximum speed which can bc achieved, using the gcar-box ratio which gives the highest road specd.

\subsection{Statement of results}

All readings taken on the sound level metcr should be stated in the report.

The basis of horsepower rating, if appropriatc, should be stated in the report.

The state of loading of the vchicle should also be specified in the report. 


\section{A1. MLASI REMENTS WITII STATIONARY VHHICLES}

\section{A1.1 Measuring positions}

Measurements are made in each of the four main directions at a distance or $7.0 \mathrm{~m}$ from the nearest surface of the vehicle. The actual positions uscd for the measurements are shown in Figure 2. If measurements are required in more than the four measuring positions shown in Figure 2, they should be taken from chosen positions on the circles shown - i.e. the circles with radius $7.0 \mathrm{~m}$.

The microphone should be located $1.2 \mathrm{~m}$ above the ground lcrel.

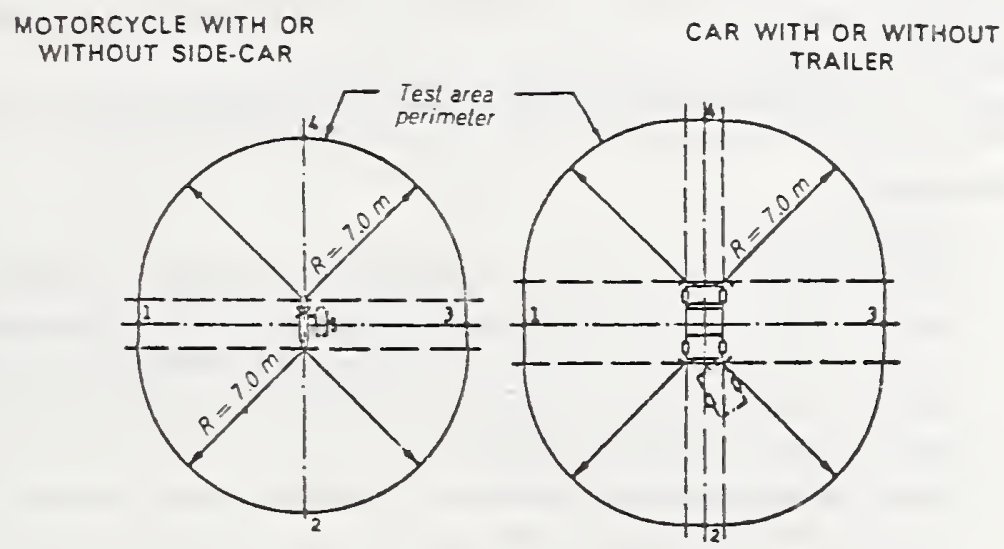

Fig. 2. - Measuring posilions for measurement with stalinnary vehicles

\section{A1.2 Number of measurements}

At least two measurements should be made in each mcasuring position.

\section{A 1.3 Vehicle conditions}

The engine of the vehicle without a speed governor should be run at three quarters of the number of revolutions per minute at which. according to the manufacturer. it develops its maximum power. The engine speed. expressed in revolutions per minute. is measured by means of an independent instrument, e.g. by the use of free-running rollers and a tachometer. A governed engine should be run at maximum spced.

The engine should be brought to its usual working lamperature before measurcments are carried out.

\section{A1.4 Statement of results}

All the sound level readings obscrved in cach measuring position should he stated in the report. 


\section{A2. MEASUREMENTS WITH VEHICLES IN MOTION (MODIFIED METHOD)}

\section{A 2.1 Testing ground}

The testing ground should be substantially level, and its surface texture such that it does not cause excessive tyre noise.

\section{A 2.2 Measuring positions}

The distance from the measuring positions to the reference line $C C$ (Fig. 1) on the road should be $7.5 \mathrm{~m}$. The path of the centre line of the vehicle should follow as closely as possible the line $C C$.

The microphone should be located $1.2 \mathrm{~m}$ above the ground level.

\section{A 2.3 Number of measurements}

At least two measurements should be made on each side of the vehicle as it passes the measuring positions.

NoTE. - It is recommended that preliminary measurements be made for the purpose of adjustment. Such preliminary measurements need not be included in the final result.

\section{A 2.4 Test procedure}

\section{A2.4.1 General conditions}

The vehicle approaches the line $A A$ in the appropriate conditions specified below:

When the front of the vehicle reaches the position, in relation to the microphone, shown as $A A$ in Figure 1 , the throttle is fully opened as rapidly as practicable and held there until the rear of the vehicle reaches position $B B$ in Figure 1, when the throttle is closed as rapidly as possible.

Trailers, including the trailer portion of articulated vehicles, are ignored when considering the crossing of line $B B$.

Note.-If the vehicle is specially constructed with equipment (such as concrete mixers, compressors, pumps, etc.), which is used whilst the vehicle is in normal service on the road, this equipment should also be operating during the test.

A2.4.2 Particular conditions

Vehicles should be driven in such a manner as to comply with either of the following conditions:

A2.4.2.1 Vehicle WITH a MaNually operated gear box, With or Without automatic CLUTCH. The vehicle should approach the line $A A$ (Fig. 1) at 8 steady speed corresponding to three quarters of the revolutions per minute at which the engine (according to the manufacturer) develops its maximum power. The gear ratio should be chosen such that the road speed most closely approaches $50 \mathrm{~km} / \mathrm{h}$ at this engine speed. However, if the vehicle has more than three forward gears, the first gear should not be used.

A2.4.2.2 Vehicle With an automatic Gear box. The vehicle should approach the line $A A$ at a steady speed of $50 \mathrm{~km} / \mathrm{h}$ or at three quarters of its maximum speed, whichever is the lower. Where alternative forward drive positions are available, the position which results in the highest sound level of the vehicle should be selected.

The selector position which is used only for engine braking, parking or similar slow manœuvres of the vehicle should be excluded.

\section{A 2.5 Statement of results}

All readings taken on the sound level meter should be stated in the report.

The basis of horsepower rating, if appropriate, should be stated in the report.

The state of loading of the vehicle should also be specified in the report. 
DEPARTMENT OF TRAISPORTATIOIT, FEDERAL HIGIWAY

ADMINISTRATION; VEHICLE IMTERIOR NOISE LEVELS

(Tit_e 49, Coaje of Federal Regulations, Chapter III, Subchapter B, Part 393.94, 38 FR 30880, November 8, 1973)

$$
\begin{aligned}
& \text { Title } 40 \text {-- Transportation } \\
& \text { CHAPTER III -- FEDERAI HIGHWAY ADUINISTRATION, } \\
& \text { DEPARTHENT OF TRHNSPCRTATION }
\end{aligned}
$$

Subchaoter 3 -- Motor Carrier Safety Regulations

[Docket iro. MC-22; Notice No. 73-27]

PART 393 -- PARTS AIT ACCESSORIES NECESSARY FOR SAFE OPERATION

Vehicle Interior Nioise Levels

393.94 Vehicle interior noise levels

(a) Application of the rules in this section. This section apolies to all motor vehicles manufactured on and after october 1, 1974. On and after April 1, 1975, this section applies to all motor vehicles marufactured before October 1, 1974 .

(b) General rule. The interior sound level at the driver's seating position of a motor vehicle must not exceed $90 \mathrm{~dB}(\mathrm{~A})$ when measured in accordance with paragraph (c) of this section.

(c) Test procedure. (1) Park the venicle at a location so that no large reflecting surfaces, such as other vehicles, signboards, buildings, or hills, are within 50 feet of the driver's seating position.

(2) Close all vehicle doors, windows, and vents. Tum off all poweroperated accessories.

(3) Place the driver in his normal seated position at the vehicle's controls. Evacuate all occupants except the driver and the person conducting the test.

(4) Use a sound level meter $w$ ich meets the requirements of the American National Standards Institute Standard ANSI S1.4-1971 Specification for Sound Level Meters, for Type 2 Meters. Set the meter to the A-weighting network, "fast" meter response.

(5) Locate the microphone, oriented vertically upward, 6 inches to the right of, in the same plane as, and directly in line with, the driver's right ear.

(6) With the vehicle's transmission in neutral gear, accelerate its 
engine to either its maximum governed engine speed, if it is equipped with an engine governor, or its speed at its maximum rated horsepower, if it is not equipped with an engine governor. Stabilize the engine at that speed.

(7) Observe the A-weighted sound level reading on the meter for this stabilized engine speed condition. Record that reading, if the reading has not been influenced by extraneous nojse sources such as motor vehicles operating on adjacent roadways.

(8) Return the vehicle's engine speed to idle and repeat the procedures specified in paragraphs (c) (6) and (c) (7) of this section until two maximum sound levels within $2 \mathrm{~dB}$ of each other are recorded. Numerically average those two maximum sound level readings.

(9) The average obtained in accordance with paragraph (c) (8) of this section is the vehicle's interior sound level at the driver's seating position for the purpose of determining whether the vehicle conforms to the rule in paragraph (b) of this section. However, a $2 \mathrm{~dB}$ tolerance over the sound level limitation specified in that paragraph is permitted to allow for variations in test conditions and variations in the capabilities of meters.

(FR Doc. 73- 23768 Filed 11-7-73;8:45 am) 
11. Appendix C. Bus Noise Reduction: Domestic and Foreign

Historically, buses have been much more of a way of life in Europe than in the United States. In response to the market demand for city buses, European manufacturers have had the economic incentive to incorporate the fairly major modifications necessary to achieve significant noise reduction. Typical modifications include: (1) redesign of the rear of the bus body to accomodate more engine shielding, (2) use of electric demand fans or viscous-coupled fans, (3) addition of engine enclosures, ( $L$ ) water cooled exhaust manifolds and (5) improved mufilers.

U. S. manufacturers have not had the same incentive due to the existence of the automobile as the primary mode of every day transportation. Bus designs have remained essentially stable for the last 15-20 years -the exception being the recent introduction of the minibus concept of transportation. Bus noise levels have been reduced in order to meet state and local noise ordinances, however, few, if any, manufacturers have made serious attempts to solve the design problems that would be necessary for substantial noise reduction on existing bus models. They are reluctant to redesign their existing buses since there is a high probability that within the next several years the overall design of buses will be significanty changed from today's design as a direct result of the Transbus Program. The Transbus Program is a demonstration project, sponsored by the U. $S$. Department of Transportation, Uroan Mass Transportation Administration (UMTA), which has as its objective the development of a totally ner concept bus design by 1977. Interior and exterior noise level considerations are included as major design parameters. Presently, AM General Corporation, Rohr Industries (Flexible) and the Truck and Coach Division of the General Motors Corporation are designing and testing prototype buses under the direction of the orime contractor -- Booze Allen Applied Research. The Rohr and AM General prototype designs utilize diesel power olants wille the GMS design incorporates a gas turbine engine. However, all three designs can accomodate either type of power plant. Nanufacturers are closely monitoring the progress of this program with results to be made public within the next several years.

\section{References}

[1] Code of Federal Regulations, 49 CER 390.3, Federal Wotor Carrier Safety Regulations: Definitions, U. S. Government Printing Office, Washington, D. C., October 1973, ‥232.

[2] Control of Noise from Notor Vehicles, Report of the Task Eorce on Noise, June 1974, Illinois Institute for Environmental Quality, Chicago, Illinois.

[3] Code of Federal Regulations, $49 \mathrm{CFR} 568.3$, Vehicles Yanufacturea in Two or More Stages: Definitions, U. S. Government Printing Office, Washington, D. C., October 1973, p. 375. 
44] Aiken, T., Federal Highway Statistics, Federal Highway Administration, personnal communication, June 3, 1975.

[5] Warnix, J. L. and Sharp, B. H., Cost Effectiveness Study of Major Sources of Noise, Volume IV, Buses, Wyle Research Report WR 73-10 (Wyle Laboratories, El Segundo, California, April 1974).

[6] Singh, J., Renner, R. A. and Saxton, J. G., The Impact of. Noise Abatement Standards upon the Bus Industry, IRT-346-R (International Research and Technology Corporation, Arlington, Virginia, March 1974).

[7] A Study of Annoyance from Motor Vehicle Noise, Bolt Beranek and Newman, Inc., Report No. 2ll2 (Bolt Beranek and Newman, Inc., Cambridge, Massachusetts, June 1971).

[8] Society of Automotive Engineers, Inc., J366b - Exterior Sound Level for Heavy Trucks and Buses, SAE Recommended Practice (SAE, New York, New York 1974 ).

[9] Measurement of Noise Emitted by Vehicles, ISO Recommendation R362 (International Organization for Standardization, Geneva, Switzerland, 1974).

[10] California Administrative Code, Title 13, Chapter 2, Subchapter 4, Article 10, Vehicle Noise Measurement (Department of the California Highway Patrol, California, December 1973).

[11] American Standard Specifications for Sound Level Meters, S1.4-1971, American National Standards Institute, New York, New York (April 1971 ).

[12] Society of Automotive Engineers, Inc., J184 - Qualifying a Sound Data Acquisition System SAE Reconmended Practice (SAE, Warrendale, Pennsylvania, 1970).

[13] Recommendations for Sound Level Meters, IEC Pulbication 123 (International Electrotechnical Commission, Geneva, Switzerlard, 1961).

[14] Recommendation for Precision Sound Level Meters, IEC Pub].ication 179 (International Electrotechnical Commission, Geneva, Switzerland, 1965).

[15] Recommendations for Octave, Half-Octave, anā Third-Octave Band Filters Intended for the Analysis of Sounds and Vibrations, IEC Publication 225 (International Electrotechnical Commission, Geneva, Switzerland, 1966).

[16] American Standard Methods for the Measurement of Sound Pressure Levels, S1.13-1971, American National Standards Institute, New York, New York (July 1971). 
[17] Transportation Noise and Noise from Equipment Powered by Internal Combustion Engines, Report No. NTID 300.13, December 1971, U. S. Environmental Protection Agency, Washington, D. C.

[18] Staadt, R. I., Truck Noise Control, SAE Report SP-386 (Society of Automotive Engineers, New York, New York, 1974).

[19] Close, W. H., Chief, Research Division, Office of Noise Abatement, U. S. Department of Transportation, personnal communication, February 28, 1974 .

[20] Landis, E. E., International Harvester Company, private correspondence, April 19, 1974. 


\section{Bibliography}

1. Transportation Noise and its Control, Department of Transportation P 5630.1, June 1972, U. S. Department of Transportation, Washington, D. C. (Available from the Superintendent of Documents, U. S. Government Printing Office, Washington, D. C., Stock Number 500-0057).

2. Transit Bus Noise Control Feasibility Study, Submitted to the Urban Mass Transportation Administration under Contract IT-06-0022, (Washington Metropolitan Area Transit Commission, Washington, D C., December 1972) Available from National Technical Information Service, Springfield, Virginia, $\mathrm{PB}-220-809$.

3. Murray, W. S. and Swetnam, G. F., Feasibility Study of Noise Control Modifications for an Urban Transit Bus, MTR 6272 Rev 2, The MITRE Corporation, McLean, Virginia, January 1973. (Available from the National Technical Information Service, Springfield, Virginia, PB-220-364).

4. Bullard, 0. J., The Determination of Practical Noise Control Retrofitting of Pre-1970 Truck and Coach Models, submitted to the Department of Transportation under Contract DOT-TCS-699, (GMC Truck and Coach Division, Pontiac, Michigan, October 1974).

5. Leasure, W. A. and Quindry, T. L., Methodology and Supporting Documentation for the Measurement of Noise from Medium and Heavy Trucks, National Bureau of Standards Internal Report 74-517, U. S. Department of Commerce, National Bureau of Standards, Washington, D. C., June 1974.

6. A Study of the Magnitude of Transportation Noise Generation and Potential Abatement, submitted to the Department of Transportation, Office of Noise Abatement under Contract No. DOT-OS-A9-018, (Serendipity Incorporated, Arlington, Virginia, September 1969). 
NBS-114A (REV. 7-73)

\begin{tabular}{|c|c|c|c|}
\hline $\begin{array}{l}\text { U.S. DEPT. OF COMM. } \\
\text { BIBLIOGRAPHIC DATA } \\
\text { SHEET }\end{array}$ & $\begin{array}{l}\text { 1. PUBLICATION OR REPORT NO. } \\
\text { NBSIR } 75-771\end{array}$ & $\begin{array}{l}\text { 2. Gov't Accession } \\
\text { No. }\end{array}$ & 3. Recipient's Accession No. \\
\hline \multicolumn{3}{|l|}{ 4. TITLE AND SUBTITLE } & 5. Publication Date \\
\hline \multirow{2}{*}{\multicolumn{3}{|c|}{$\begin{array}{l}\text { An Evaluation and Assessment of Existing Data and Procedures } \\
\text { for the Measurement of Noise from Buses }\end{array}$}} & September 1975 \\
\hline & & & 6. Performing Organization Code \\
\hline \multicolumn{3}{|c|}{ 7. AUTHOR(S) B. R. Fuller, W. A. Leasure, Jr. } & 8. Performing Organ. Report No. \\
\hline \multirow{2}{*}{\multicolumn{3}{|c|}{$\begin{array}{l}\text { 9. PERFORMING ORGANIZATION NAME AND ADDRESS } \\
\text { NATIONAL BUREAU OF STANDARDS } \\
\text { DEPARTMENT OF COMMERCE } \\
\text { WASHINGTON, D.C. } 20234\end{array}$}} & $\begin{array}{l}\text { 10. Project/Task/Work Unit No. } \\
2000451\end{array}$ \\
\hline & & & 11. Contract/Grant No. \\
\hline \multicolumn{3}{|c|}{ 12. Sponsoring Organization Name and Complete Address (Street, City, State, ZIP) } & $\begin{array}{l}\text { 13. Type of Report \& Period } \\
\text { Covered }\end{array}$ \\
\hline \multirow{2}{*}{\multicolumn{3}{|c|}{$\begin{array}{l}\text { Office of Noise Abatement and Control } \\
\text { U. S. Environmental Protection Agency } \\
\text { Washington, D. C. } 20460\end{array}$}} & Final \\
\hline & & & 14. Sponsoring Agency Code \\
\hline
\end{tabular}

15. SUPPLEMENTARY NOTES

16. ABSTRACT (A 200-word or less faclual summary of most significant in formation. If document includes a significant bibliography or literature survey, mention it here.)

This report reviews existing bus noise measurement procedures with regard to their usefulness in the regulation of bus noise as well as the availability, extent and applicability of existing data. On the basis of this review, probable or potential measurement difficulties are identified that could hinder the promulgation and/or enforcement of future EPA regulations to control the noise emission from buses.

17. KEY WORDS (six to twelve entries; alphabetical order; capitalize only the first leller of the first key word unless a proper name; separated by semicolons)

Acoustics (sound); bus; measurement methodology; noise emission standard; noise measurement.
18. AVAILABILITY
[*] Unlimited

[X] For Official Distribution. Do Not Release to NTIS

[ Order From Sup. of Doc., U.S. Government Printing Office Washington, D.C. 20402 , SD Cat. No.C13

[] Order From National Technical Information Service (NTIS) Springfield, Virginia 22151

\begin{tabular}{|l|c|}
\hline $\begin{array}{l}\text { 19. SECURITY CLASS } \\
\text { (THIS REPURT) }\end{array}$ & 21. NO. OF PAGES \\
UNCLASSIFIED & 50 \\
\hline $\begin{array}{l}\text { 20. SECURITY CLASS } \\
\text { (THIS PAGE) } \\
\text { UNCLASSIFIED }\end{array}$ & 22. Price \\
\hline
\end{tabular}




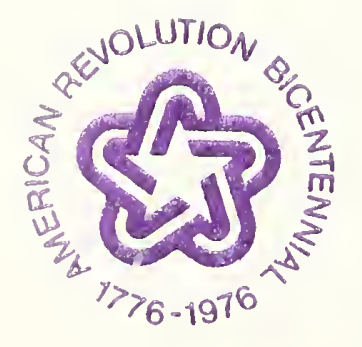

